\title{
Resiliencia Económica Empresarial: Aproximación al Concepto y sus Dimensiones
}

\author{
Wilfredo Charry Trujillo \\ Estudiante de Administración de Empresas
}

Facultad de Administración de Empresa - Universidad Santo Tomás Sede Bogotá

\begin{abstract}
RESUMEN
El objetivo de este trabajo es identificar y analizar desde la perspectiva del concepto de resiliencia, los diferentes factores que la definen, partiendo desde el ámbito de las ciencias sociales y naturales, hasta enfocarnos en la resiliencia en el ámbito de las ciencias administrativas, extrayendo algunas ideas preliminares y sus aportes para la disciplina de resiliencia económica empresarial.

El estudio realizado sobre la resiliencia empresarial abarcó diferentes autores que definen un modelo de acción para las organizaciones resilientes cuando surge estrés organizacional y crean un modelo, logrando identificar los procesos de cambio que las organizaciones deben implementa para fortalecer su desarrollo.

Posteriormente se estructura un modelo de matriz, a partir del cual ese hace un acercamiento a la identificación de las dimensiones, variables e indicadores que podrían facilitar la medición de la resiliencia en una organización, Esta matriz permitió identificar diferentes aspectos que muestran la situación de la organización respecto a características administrativas, financieras y operacionales.

El resultado de la matriz es una guía sobre cómo hacer que las organizaciones alcancen un mayor fortalecimiento, nuevos aprendizajes y capacidad de adaptabilidad para los tiempos de tensión e incertidumbre.
\end{abstract}

Palabras clave: Crisis, Dimensión, Indicadores, Iniciativa, Interacción, Liderazgo, Mutabilidad, Organización, Resiliencia económica empresarial, resiliente, Variable.

\begin{abstract}
ABSTRAC
The objective of this study is to identify and analyze from the perspective of the concept of resilience, the different factors that define it, starting from the field of Social and Natural Sciences, to focus on resilience in the field of Administrative Sciences, extracting some preliminary ideas and its contributions to the discipline of business economic resilience.

It is then structured a matrix model, from which an approach to the identification of the dimensions, variables and indicators that could facilitate the measurement of resilience in an organization, that makes this matrix identified different aspects that show the status of the organization with respect to administrative, financial and operational characteristics.
\end{abstract}

The result of the matrix is a guide on how to make the organizations to achieve a further strengthening, new learning and adaptability ability for times of tension and uncertainty. 
Key words: Crisis, Dimension, indicators, initiative, interaction, leadership, mutability, organization, business economic resiliency, resilient, Variable

\section{OBJETIVOS}

\section{General:}

Identificar y analizar desde la perspectiva del concepto de resiliencia, los factores que permiten potencializar las habilidades para el crecimiento y sostenibilidad de una organización, proponiendo una estructura de modelo que facilite su medición.

\section{Específicos:}

$\checkmark$ Conocer la interpretación que las diferentes disciplinas dan al concepto de resiliencia.

$\checkmark$ Identificar indicadores a partir de los cuales se pueda medir y promover la resiliencia organizacional.

$\checkmark$ Proponer elementos preliminares para un modelo que permita determinar el nivel de resiliencia de una organización.

\section{JUSTIFICACION}

El concepto de la resiliencia organizacional es un tema que ha ganado importancia en el mundo de los negocios en los últimos años, pues prácticamente todos los propietarios y directores de empresas están interesados en identificar los factores por los cuales algunas personas y organizaciones sumergidas en dificultades y cambios bruscos, mantienen excelentes resultados y adecuados rendimientos.

En este sentido el enfoque de la resiliencia organizacional parte de la premisa que las organizaciones son parte activa del entorno cada vez más cambiante, regido por inestabilidad política, económica, social y medioambiental y más que centrarse en las causas que generan esta situación, la resiliencia organizacional se preocupa de observar aquellas condiciones que posibilitan el adaptarse y desarrollarse de una manera más eficaz y eficiente. 
En esta investigación, al identificar las variables relacionadas con la resiliencia organizacional se está aportando conocimiento valioso sobre lo que identifica a una organización resiliente, para desarrollar una capacidad a partir del aprendizaje.

Conocer aquellos factores que contribuyen a la creación de resiliencia organizacional, identificar la manera de crear ventaja competitiva, entender la forma de administrar las adversidades internas y externas, enfrentándolas, sobreponiéndolas y aprendiendo de ellas para fortalecerse. Todo esto de manera simultánea justifica el desarrollo de la presente investigación y se convierte en un punto inicial para futuras investigaciones.

\section{INTRODUCCIÓN}

La investigación realizada se fundamenta inicialmente en relación al origen del concepto de resiliencia; de allí se parte para identificar los diferentes ámbitos de resiliencia que actualmente existen dentro del campo de investigación, a continuación se abarcará este término desde diferentes autores que lo definen desde su parte etimológica, para luego explicarlo desde diferentes campos de investigación como las ciencias sociales y naturales y administrativas.

La Real Academia Española, describe el término a nivel psicológico como capacidad humana de asumir con flexibilidad situaciones límite y sobreponerse a ellas. "F. Psicol. Capacidad humana de asumir con flexibilidad situaciones límite y sobreponerse a ellas. (RAE, 2015)".

Ha sido definido por el American Heritage Dictionary (1994) como "la habilidad para recuperarse rápidamente de la enfermedad, cambio o infortunio". La palabra resiliente ha sido generalmente aplicada a las personas que se sobreponen a las dificultades.

En relación al origen del concepto, el vocablo resiliencia proviene del término latino resilium, que significa volver atrás, volver de un salto, volver al estado inicial y rebotar. Originariamente fue usado para referirse a la cualidad de elasticidad y plasticidad de una sustancia (Conrad, 2002).

Viene del Latín salire, se puede traducir como: "saltar hacia atrás, rebotar, ser repelido, surgir", con el prefijo "re", que indica repetición, reanudación. "Resiliar" es desde luego rebotar, reanimarse, ir hacia delante, después de haber padecido un golpe o vivido una situación traumática "También consiste en hacer un contrato con la adversidad". Es, en cierto sentido, asimilable a la elasticidad, es utilizado el término para expresar la capacidad 
de un material de recobrar su forma original después de haber sido sometido a altas presiones. (Campo, 2012)

Resiliencia: Significa volver a la normalidad, y es un término derivado del latín (del verbo resilio, resilire: "saltar hacia atrás, rebotar"). Otros autores la definen como... volver a la normalidad, volver al estado natural, especialmente después de alguna situación crítica e inusual. (Alvarez, 2014).

Igualmente la resiliencia en la física es la propiedad de los materiales que acumulan energía, cuando se someten a situaciones de estrés, tales como rupturas. Estos materiales, después de un momento de tensión, pueden o no ser dañados, y en este último caso, tienen la capacidad de volver a la normalidad. Es una magnitud que cuantifica la cantidad de energía por unidad de volumen que almacena un material al deformarse elásticamente debido a una tensión aplicada. (Alvarez, 2014)

También para las ingenierías, se llama resiliencia de un material a la energía de deformación que puede ser recuperada de un cuerpo deformado cuando cesa el esfuerzo que causa la deformación. La resiliencia es igual al trabajo externo realizado para deformar un material hasta su límite elástico. Es la capacidad de memoria de un material para recuperarse de una deformación, producto de un esfuerzo externo. (Fisher, 2006)

En sistemas tecnológicos, la resiliencia es la capacidad de un sistema de soportar y recuperarse ante desastres y perturbaciones. (Barquilla, 2014)

En esta última década han tomado relevancia los escenarios de formación en este concepto, tanto en sus aspectos teóricos como en su aplicación en diferentes poblaciones; se encuentran opciones de seminarios, diplomados, encuentros internacionales y congresos que cuentan con la presencia de investigadores y autores de reconocimiento mundial. Es ya conocido que el término tiene su origen en la física y es en este ámbito internacional donde se fue dando cuerpo al término resiliencia.

\section{$\underline{\text { Resiliencia en el ámbito de las ciencias sociales }}$}

El término fue adaptado a las ciencias sociales para describir a aquellas personas que, a pesar de vivir en ambientes difíciles en los que existe un alto riesgo de perecer, se desarrollan psicológicamente sanos y exitosos; ello implica el desarrollo de la capacidad para recobrarse ante la adversidad, adueñándose de mayores recursos como respuesta a las crisis y desafíos de la vida. (Walsh F. , 2004) 
Las investigaciones sobre resiliencia mencionan ciertos rasgos característicos de las personas resilientes: habilidades para resolver problemas, alta autoestima, esperanza realista, buen control personal, tenacidad, percepción del cambio como algo favorable, percepción de tener control sobre los sucesos, fe y espiritualidad, optimismo, y emociones positivas como el humor y la risa. (Counsins, 1979).

También dentro de los aportes podemos ver que las creencias, la capacidad de organización familiar y de comunicación eficaz son aspectos indispensables para lograr que una familia afronte del modo más saludable posible el desafío que implica un trastorno mental, lo cual dará como resultado la percepción de apoyo y crecimiento en el sistema familiar. Pero estas situaciones de crisis no se dan únicamente por trastornos mentales, sino también por crisis de actitudes, errores etc.

Resiliencia individual: La resiliencia aparece actualmente como una palabra común en la vida cotidiana, sin embargo no existe un consenso sobre su definición ya que son muchos los autores, incluso las marcas comerciales, que incorporan el concepto en sus trabajos. (Fraser, 1999), desde la disciplina de Trabajo Social, han sugerido que la resiliencia implica (1) sobreponerse a las dificultades y tener éxito a pesar de estar expuestos a situaciones de alto riesgo; (2) mantener la competencia bajo presión, esto quiere decir saber adaptarse con éxito al alto riesgo y (3) recuperarse de un trauma ajustándose de forma exitosa a los acontecimientos negativos de la vida.

En una visión similar Masten (1994) había sostenido que la resiliencia se refiere a (1) personas de grupos de alto riesgo que han obtenido mejores resultados de los esperados; (2) buena adaptación a pesar de experiencias estresantes (cuando los estresores son extremos la resiliencia se refiere a patrones de recuperación) y (3) recuperarse de un trauma. A pesar de las diferencias en terminología, la resiliencia tiene que entenderse como un proceso.

En este sentido (Masten, 1998) Entienden la resiliencia como constructo dinámico que incluye una amplia clase de fenómenos implicados en las adaptaciones exitosas en el contexto de amenazas significativas para el desarrollo. La resiliencia, aunque requiere una respuesta individual, no es una característica individual ya que está condicionada tanto por factores individuales como ambientales, emergiendo de una gran heterogeneidad de influencias ecológicas que confluyen para producir una reacción excepcional frente a una amenaza importante. 
Algunos autores conceptualizan la resiliencia en función o en comparación con los procesos y situaciones de riesgo psicosocial, proponiendo que las conductas resilientes son los resultados positivos frente a dichos riesgos y que implican competencias individuales, familiares e interpersonales. Para Rutter $(1985,1999)$ la resiliencia se comprende como la variación individual en la manera en la que las personas responden a los riesgos a lo largo del tiempo. Por otro lado Kirby y Fraser (1997) relacionan riesgo y resiliencia formando un continuo, en el que cada dimensión representa el lado opuesto de la otra.

Otros autores (Dyer y McGuinnes, 1996) entienden la resiliencia como un concepto global, multifacético, asociado con numerosas características individuales y multisistémicas. En esta línea Grotberg (1995) entiende este concepto como una capacidad universal que permite a las personas, familias, grupos o comunidades prevenir, minimizar o sobreponerse a los efectos dañinos de la adversidad, o a anticipar adversidades inevitables. Para este autor las conductas resilientes pueden responder a la adversidad por una parte manteniendo la calma y el desarrollo normal a pesar de la adversidad y por otra promoviendo el crecimiento personal más allá del nivel presente de funcionamiento (Grotberg, 1995: 2).

Resiliencia Académica El concepto de resiliencia y su medición En el área de las Ciencias Sociales y la Educación, se distinguen definiciones de resiliencia que comparten aspectos como: a) reconocer que es una capacidad humana más o menos universal (Grotberg, 1995; Rutter, 1993); b) está presente la idea de adversidad, estrés o contexto negativo (Grotberg, 1999; Manciaux, 2005); c) el sujeto es quien enfrenta las adversidades (Goodyer, 1995; Kreisler, 1996; Masten, 1990) y d) se obtiene como resultado una adaptación positiva (Goodyer, 1995; Lutha \& Cicchetti, 2000; Vanistendael, 2002).

La resiliencia más allá de ser una condición permanente y dependiente de factores externos a la persona, es una construcción propia y que varía según los contextos y los momentos en que ocurre (Saavedra, 2003). En último término, el considerarse resiliente o no será un evaluación interna que hace el sujeto frente a su vida. La medición de la resiliencia debe integrar una concepción dinámica que resalte el papel del sujeto en esta evaluación, sin desconocer que existen aspectos estructurales de la persona que sirven de base para la construcción de la conducta resiliente (Saavedra \& Villalta, 2008a).

La articulación entre distintos enfoques actuales de la resiliencia (Grotberg, 1995; Guidano, 1994; Saavedra, 2003) permite generar un camino de respuesta, que considere diferentes dimensiones internas de la persona, como lo hacen los modelos de Grotberg 
(1995) y de Saavedra (2003), que recogen el sentido histórico de la respuesta ante el obstáculo. En esta dirección, la escala SV-RES (Saavedra \& Villalta, 2008a) considera modalidades de interacción del sujeto: a) consigo mismo, b) con los otros y c) con sus posibilidades, en relación con acciones para aprender y transformar proactivamente sus juicios, sobre 1) la capacidad de generar metas orientadoras de la acción, 2) la capacidad para resolver una situación problemática, 3) la definición de sí mismo y 4) la definición de la historia que la constituye como tal.

En educación, la resiliencia es un proceso de superación de la adversidad y de responsabilidad social. La tarea pedagógica es el diseño de acciones preventivas tanto individuales, grupales e institucionales, pero una prevención en donde la percepción de las personas sea concebida con sus propios recursos para desarrollar su resiliencia y ser, a la vez, un recurso para otro.

Resiliencia Psicológica: Más recientemente, el propio Luthar (2003) define el término de resiliencia como "la manifestación de la adaptación positiva a pesar de significativas adversidades en la vida" (p.xxix). De modo semejante, Masten y Powell (2003) indican que la resiliencia se refiere a "patrones de adaptación positiva en el contexto de riesgos o adversidades significativas" (p. 4). Para ellos, la resiliencia sería la descripción de un patrón general más que un diagnóstico. Por ello considera que lo más apropiado sería decir "esta persona tiene un patrón resiliente", o "esta persona muestra las características de la resiliencia". No la consideran como un rasgo de un individuo, ya que la misma puede variar a lo largo del tiempo y de las etapas de la vida, manifestada en conductas y patrones en la vida.

En la revisión de Fergus y Zimmerman (2005) indican que la resiliencia se refiere al proceso de superar los efectos negativos de la exposición al riesgo, afrontamiento exitoso de las experiencias traumáticas y la evitación de las trayectorias negativas asociadas con el riesgo. Para que aparezca la resiliencia tienen que estar presentes tanto factores de riesgo como de protección que ayuden a conseguir un resultado positivo o reduzcan o eviten un resultado negativo.

La resiliencia, además, se centra en la exposición al riesgo en los adolescentes y, también, se basa más en las fuerzas que en los déficits de los individuos. Es indudable la gran atención que en los últimos años está recibiendo el concepto de resiliencia, tanto en el campo de la salud mental en general (Institute of Medicine, 1994) como en el de las drogodependencias en particular (ej., Glantz y ohnson, 1999, Luthar, 2003). 
A nivel de estudios, el concepto ha mostrado su poder explicativo en toda una serie de estudios longitudinales que han mostrado la importancia y relevancia del concepto para explicar la adaptación exitosa de muchas personas en su vida adulta que pasaron por traumas o eventos vitales negativos en su infancia.

Resiliencia Social: Según Edith Castelán (Edición: 289). La Resiliencia es la capacidad humana de sobreponerse a los riesgos de la existencia y no sólo superarlos, sino desarrollar el potencial personal al máximo.

La resiliencia — como combinación de factores que permiten a la persona afrontar y superar los problemas y adversidades de la vida-, se caracteriza por un conjunto de procesos sociales intrapsíquicos que posibilitan una existencia sana, viviendo en un medio insano.

La naturaleza de la resiliencia es dinámica, es la armonía entre los factores personales, familiares, sociales, protectores y de riesgo. No es un estado estático, definido y estable, sino un camino de continuo crecimiento. La tarea educativa se basa en estudiar los procesos de la resiliencia, considerando todas y cada una de las dimensiones de la persona.

La resiliencia la construye el ser humano en función de sí mismo y del contexto, insertado en un proceso complejo donde interviene directamente la voluntad y las competencias afectivas. Así, la resiliencia demuestra que no existe ningún determinismo genético o del medio ambiente en la persona humana. Es el medio para abrir el campo a la creatividad y al correcto ejercicio de la libertad; requiere mantener viva la curiosidad; atreverse a experimentar; abrir los sentidos y la mente a la paradoja; usar la lógica y la imaginación; y ser responsable de sí mismo.

La resiliencia se manifiesta como un proceso de acción sistemática en el que intervienen diferentes factores para promover el desarrollo integral de la persona a pesar de sus difíciles condiciones de vida; son claves aquí el contacto humano (entendimiento y palabra), los afectos y la solidaridad, sin perder contacto con la realidad.

La resiliencia es un continuo que refuerza las opciones y oportunidades de las personas, mediante la aplicación de sus capacidades y recursos internos para enfrentarse a situaciones de riesgo que pueden ponerlas en peligro; las capacidades personales para afrontar las dificultades, incluyendo en el juego sus aptitudes. Las investigaciones en resiliencia han cambiado la percepción del ser humano, pasando de un modelo centrado 
en el riesgo, a un modelo de prevención basado en las potencialidades, en los recursos que el ser humano posee y en la relación con su entorno (Manciaux, et al., 2003).

Resistir es una estrategia que le permite a la persona crear para llegar a su autonomía. Resistir es crear las condiciones. Y el proceso de creación es positivo. Pero la resiliencia es el medio para conseguir la obra personal — de cada quien- que son sus finalidades, metas, objetivos, propósitos; lograr el fin mismo del hombre, vivir en plenitud, no haciendo cosas buenas, sino siendo buena persona; es necesario hacer cosas buenas para alguien, para sí mismo, para los otros. De lo contrario, la resiliencia se convierte en una doctrina del sobreviviente (reality show).

Resiliencia Ecológica: El término también en el contexto de la ecología, es la capacidad de un determinado sistema que le permite recuperar el equilibrio después de haber sufrido una perturbación. Este concepto se refiere a la capacidad de restauración de un sistema. El término de resiliencia del medio ambiente fue conocido a partir de 1970, gracias al trabajo del famoso ecologista canadiense (C. S. Holling.)

Con relación a lo que el anterior autor menciona se puede deducir que la resiliencia es más que todo una recuperación una nueva etapa o transformación de algo que se ha perdido está inmersa en la capacidad que tiene una persona o un grupo de recuperarse frente a la adversidad para seguir proyectando el futuro. En ocasiones, las circunstancias difíciles o los traumas permiten desarrollar recursos que se encontraban latentes y que el individuo desconocía hasta el momento.

Cabe mencionar que el concepto también se utiliza en ecología para hacer referencia a aquellas comunidades que pueden superar los cambios momentáneos en el medio sin modificar su forma de interactuar con él. Un ecosistema con buena resiliencia es aquel que contiene una gran cantidad de especies y esa diversidad es lo que le permite sobrellevar las diversas perturbaciones que pudieran surgir en el entorno.

Dentro de esta misma idea de supervivencia, otras variantes del concepto en la ecología son la capacidad que tiene un sistema para auto gestionarse y organizarse, lo cual estaría ligado firmemente al punto anterior (el sistema reuniría las herramientas que necesita para enfrentarse a los cambios sin que estos generen una transformación en las bases de dicho espacio). 


\section{Resiliencia en el ámbito de las ciencias administrativas}

El concepto recoge aportes de las ciencias sociales y del comportamiento en escenarios comunitarios, pero tiene una evidente validez para analizar los procesos de cambio y de crisis en el ámbito organizacional-empresarial. Es probable que desde esta óptica aparezcan propuestas concretas para enfrentar la crisis que padece nuestra región. Independencia, relación, iniciativa, humor, creatividad, moralidad. Generalmente cuando se aborda el tema de las crisis en las empresas nos referimos a sus resultados finales en términos de mercado, de finanzas o de producción. No se estudian en profundidad los procesos, las decisiones y las conductas que obtuvieron los resultados. Los comportamientos tanto colectivos como individuales que ayudaron a sortear la crisis y que en el fondo son los potenciadores de los resultados, generalmente pasan a un segundo plano. Se define la resiliencia como la capacidad de una persona o de un sistema social para desarrollarse y crecer en presencia de grandes dificultades. (Vanistendael, Resilience: a few key, 1994)

Las empresas resilientes son aquellas capaces de absorber cambios y rupturas, tanto internos como externos, sin que por ello se vea afectada su rentabilidad y que incluso desarrollan una flexibilidad tal que, a través de procesos de rápida adaptación, logran obtener beneficios extras, sean éstos pecuniarios o intangibles, derivados de circunstancias adversas y/o imprevistas. (Rosales, 2015)

La resiliencia empresarial hace referencia a la capacidad que tiene cada organización para sobreponerse de las adversidades por las que atraviesa ya sean internas o externas ayudándose de lo que disponen en ese momento y enfrentando la realidad de la situación en la que se encuentra para dar un significado a los tiempos difíciles y salir a delante. Su objetivo es preparar a las organizaciones para que sean más fuertes en cualquiera de sus niveles jerárquicos y lograr sus metas.

Erol et al. (2010a) la definen como la capacidad de las organizaciones para disminuir la vulnerabilidad, habilidad para cambiar y adaptarse así como la habilidad para recuperarse rápidamente ante imprevistos.

Gallopin (2006) considera la resiliencia como una capacidad adaptativa de la empresa. La describe como su habilidad para tratar, adaptarse y recuperarse ante una perturbación. En el ámbito de la gestión, la resiliencia es parte de los procesos de gestión de cambios. Las personas que trabajan en las organizaciones deben tener un gran equilibrio 
emocional, especialmente para hacer frente a los problemas del trabajo, cuando las situaciones no salen como esperaban y lo que se puede hacer para minimizar la situación.

En el ámbito de la gestión, la resiliencia es parte de los procesos de gestión de cambios. Las personas que trabajan en las organizaciones deben tener un gran equilibrio emocional, especialmente para hacer frente a los problemas del trabajo., cuando las situaciones no salen como esperaban y lo que se puede hacer para minimizar la situación.

En la Cultura Emprendedora, la resiliencia es la capacidad que tiene el emprendedor para confrontar situaciones que compliquen la generación y desarrollo de su plan de negocios o su proyecto a emprender, generando sinergia con sus socios o colaboradores para salir airoso y con determinación de ella, basado en la previsión del riesgo.

Como el objetivo de este trabajo es hacer una revisión acerca del concepto resiliencia, tomaremos como referente los diferentes estudios propuestos anteriormente para llegar a identificar y analizar los factores que permiten potencializar las habilidades para el crecimiento y sostenibilidad de una organización, proponiendo una estructura de modelo que facilite su medición.

Para ello se estudiará la resiliencia organizacional, su empleo, sus características, también otras perspectivas de las experiencias sociales y personales dentro de la empresa y se tomará como referente el modelo de Resilent Organisations, (equipo multidisciplinario de investigadores y profesionales, de las principales universidades de investigación de Nueva Zelanda.

El trabajo está orientado a organizaciones de transformación para que puedan sobrevivir con éxito grandes trastornos, evitar la disfunción crónica, construir alianzas sólidas y prosperar); como el interés es construir un modelo o propuesta vamos a identificar indicadores para medir la resiliencia económica empresarial a través de una matriz I.M.I. (Iniciativa - Mutabilidad - Interacción), donde se especificará su análisis e interpretación.

El concepto de la resiliencia organizacional es un tema que ha ganado importancia en el mundo de los negocios en los últimos años, pues prácticamente todos los propietarios y directores de empresas están interesados en identificar los factores por los cuales algunas personas y organizaciones sumergidas en dificultades y cambios bruscos, mantienen excelentes resultados y adecuados rendimientos.

En este sentido el enfoque de la resiliencia organizacional parte de la premisa que las organizaciones son parte activa del entorno cada vez más cambiante, regido por 
inestabilidad política, económica, social y medioambiental y más que centrarse en las causas que generan esta situación, la resiliencia organizacional se preocupa de observar aquellas condiciones que posibilitan el adaptarse y desarrollarse de una manera más eficaz y eficiente.

\section{$\underline{\text { Aplicación del concepto de resiliencia al ámbito empresarial }}$}

El concepto de resiliencia empresarial hace referencia a la capacidad que tienen las empresas u organizaciones de afrontar cambios de cualquier magnitud y no decaer en un momento determinado. Sino que por el contrario salir adelante en las diferentes adversidades que se pueden generar. Dificultades que pueden ser internas, que las empresas las pueden controlar como los tangibles, empleados, cambios de estructuras de maquinarias y de equipos; o vicisitudes externas como los cambios en la política gubernamental, en cambios en el ambiente como los climáticos o catastróficos; u otros problemas que pueden provenir de las dos vertientes, como los cambios en las directivas, o en los accionistas ya que siempre existen momentos en los cuales los objetivos administrativos no se están enfocando claramente hacia un mismo fin y debemos retomar la planeación, organización, dirección y control de la empresa y tener claros los puntos tanto de partida como de llegada de las organizaciones.

Para la mayoría de empresarios o personas del común el tema de resiliencia es relativamente nuevo hablando en términos económico-administrativos; aunque siempre ha estado inmerso entre nuestras diferentes comunidades ya sean psicológicas, también podemos ver el concepto en la parte ecológica; pero el tema que vamos a tocar en esta investigación se enfoca a lo relacionado con lo económico y administrativo.

Es indiscutible que la resiliencia empresarial es una realidad que todo el tiempo debe hacer presencia en las empresas, ya que existen inconvenientes ya sean internos o externos, problemas que en algunas ocasiones se pueden prever pero en algunas otras no queda ninguna salida sino afrontarlas.

Puede que el término de resiliencia económica empresarial sea un poco nuevo al menos en la lengua latina pero examinando a profundidad se sabe que ese es el diario en las empresas ya que todo el tiempo los gerentes enfrentan cambios que alteran los planes y deben trazar nuevas estrategias para cumplir el logro de metas organizacionales ya sea para seguir a delante o simplemente para generar al menos las ganancias para estar en el punto de equilibrio esperando que mejore la expectativa que las estanca, por ende en todo momento se habla de resiliencia empresarial ya sea que se espere o que como la mayoría 
de casos hay que cubrir esos vacíos a los que las empresas están destinadas a sobrevivir teniendo en cuenta el ciclo de vida empresarial: origen, crecimiento, madurez o declive y dependiendo del administrador que es el que podría ayudar a que no muera si no que le dé un empujón y tenga un nuevo ciclo de vida dependiendo de todos los factores.

La resiliencia aparece actualmente como una palabra común en la vida cotidiana, sin embargo no existe un consenso sobre su definición ya que son muchos los autores, incluso las marcas comerciales, que incorporan el concepto en sus trabajos. Fraser, Richman y Galinsky (1999), desde la disciplina de Trabajo Social, han sugerido que la resiliencia implica (1) sobreponerse a las dificultades y tener éxito a pesar de estar expuestos a situaciones de alto riesgo; (2) mantener la competencia bajo presión, esto quiere decir saber adaptarse con éxito al alto riesgo y (3) recuperarse de un trauma ajustándose de forma exitosa a los acontecimientos negativos de la vida.

En una visión similar Masten (1994) había sostenido que la resiliencia se refiere a (1) personas de grupos de alto riesgo que han obtenido mejores resultados de los esperados; (2) buena adaptación a pesar de experiencias estresantes (cuando los estresores son extremos la resiliencia se refiere a patrones de recuperación) y (3) recuperarse de un trauma.

A pesar de las diferencias en terminología, la resiliencia tiene que entenderse como un proceso. En este sentido Masten y Coatsworth (1998) entienden la resiliencia como constructo dinámico que incluye una amplia clase de fenómenos implicados en las adaptaciones exitosas en el contexto de amenazas significativas para el desarrollo. (Quesada, UAEM Redalyc.org, 2003)

Teniendo en cuenta los tres diferentes autores citados anteriormente vemos claramente que los conceptos que estamos construyendo se acoplan en la definición empresarial y vemos que está saliendo un consolidado de los que referimos con las organizaciones teniendo en cuenta fracciones de las definiciones anteriores no nos alejamos al concepto empresarial ya que bien sabemos las empresas desde que nacen hasta que mueren si es posible están en la lucha por perdurar cada vez más en el tiempo y ser altamente competitivas con las otras del mismo entorno, pero bien sabemos que esta alta competencia viene con problemas relacionados con la capacidad interna que cada una de ellas guarda para poder cubrir sus capacidades y poderse explotar y estar dentro de su emulación con las otras, dicho en otras palabras vemos que las empresas se vuelven cada vez más competitivas es para tratar de conseguir sacar las otras del mercado y las que no 
salen si no que por el contario dan la batalla son las que conocemos como resilientes ya que se adaptaron a los cambios de alta competencia.

"Una organización resiliente la posee un conjunto de capacidades orientadas a la realización de acciones de manera robusta frente a una condición específica y de transformación, casi siempre generada por el encuentro con acontecimientos inesperados y de gran alcance, que cuentan con el potencial suficiente para poner en peligro la supervivencia de una organización en el largo plazo." (Salgado, 2010)

Cada vez tenemos más en cuenta el conjunto de campos a los que las empresas pueden llegar a ser resilientes y altamente flexibles a los cambios inesperados; y se piensa más en el largo plazo puesto que en el presente, o a mediano plazo se pueden presentar fuertes competencias que serían atendidas. Cuando las empresas son resilientes los directores puede que estén más comprometidos en el funcionamiento y manejo de la empresa, se ven obligados a tener reuniones con la gerencia, tratan de cuidar en su mayoría a los accionistas, implementan nuevos estándares para reportar con mayor trasparencia la información financiera y aumentan la vigilancia de todos los procesos en gestión empresarial.

\section{La resiliencia y su empleo en las organizaciones}

El objetivo del presente artículo es analizar y discutir en torno al concepto de resiliencia y su aplicación organizacional. Además, dentro del ámbito de las capacidades individuales o de las reglas impuestas dentro de una compañía, con frecuencia estas personas poseen las habilidades necesarias y suficientes para resolver problemas sin utilizar las herramientas usuales u obvias. Por esto, se convierten en una gran fortaleza para las organizaciones.

El uso del concepto resiliencia es reciente en el campo organizacional, quizá por su origen teórico. Dentro de este campo disciplinario se le emplea como una forma de designar la capacidad de recuperación de las organizaciones ante un evento no esperado, también se le puede considerar como un detonante de acciones de previsión o como parte toral de un proceso estratégico.

La resiliencia en la organización puede ser definida como la capacidad de un sistema para absorber los cambios, que se vislumbran como una serie de crisis repentinas (López, 
2009; Smith y Graetz, 2011), y aún conservar su funcionalidad esencial (Walker et al., 2006).

Para el desarrollado de esta sección introductoria es pertinente preguntar ¿qué significa la resiliencia para las organizaciones?, ¿cuáles son las características de las organizaciones resilientes?, ¿cómo se puede emplear la resiliencia en las organizaciones? Las respuestas a estos cuestionamientos, entre otros, constituirán los temas centrales del presente artículo. Como un primer acercamiento se puede afirmar la existencia de distintas dimensiones en torno a la conceptualización de la resiliencia organizacional, como se muestra a continuación:

1. La capacidad para prevenir la ocurrencia de consecuencias negativas.

2. La capacidad de prevenir el empeoramiento de las consecuencias negativas al paso del tiempo.

3. La capacidad para recuperarse de las consecuencias negativas de un evento.

Para algunos autores la resiliencia organizacional se refiere metafóricamente, a la búsqueda de la "cubierta de plata" (buscar las oportunidades durante una crisis a fin de emerger más fuerte y en mejores condiciones a las prevalecientes antes del hecho crítico, McManus, 2008). A fin de dilucidar las preguntas, conceptos e ideas fincadas sobre la resiliencia organizacional, el trabajo se ha dividido en dos apartados: 1) características de la organización resiliente, y 2) ¿cómo se emplea la resiliencia en las organizaciones? El documento se dirige a todas las personas interesadas en el tema.

Características de la organización resiliente: Una organización resiliente la posee un conjunto de capacidades orientadas a la realización de acciones de manera robusta frente a una condición específica y de transformación, casi siempre generada por el encuentro con acontecimientos inesperados y de gran alcance, que cuentan con el potencial suficiente para poner en peligro la supervivencia de una organización en el largo plazo.

La resiliencia expresa la capacidad de una organización o de sus partes para responder rápidamente a la incertidumbre. En consecuencia, la resiliencia es un estado de la organización producido por la administración de la incertidumbre dentro de un sistema adaptativo complejo. Un indicador de este estado se encuentra en una organización con una ingente capacidad adaptativa (Dahms, 2010:22). La resiliencia no es una condición 
estática de una organización, puede variar con el tiempo en función de la naturaleza y las consecuencias de una crisis en particular.

Por lo anterior, es pertinente reconocer la existencia de un cierto grado de vinculación e interdependencia entre las organizaciones. Es decir, ninguna organización es una entidad totalmente aislada (Daft y otros, 2010:183). La resiliencia de una organización probablemente se encuentra relacionada de manera directa o indirecta con la resiliencia de otras organizaciones (clientes, proveedores, agentes gubernamentales e, incluso, competidores). Adicionalmente, una organización depende de la resiliencia individual de su personal y de las comunidades ligadas a ella en una relación simbiótica. Como resultado de esta interacción de doble vía una organización a su vez participa en el fortalecimiento de las capacidades de resistencia de dichas comunidades.

Así mismo la resiliencia de una organización se relaciona directamente con la de su sector, y la solidez del sistema está entrelazada con la de la nación. La concatenación de estos distintos momentos de resiliencia ofrece en todos los ámbitos tanto retos como oportunidades. El desafío proviene de la sensación de "la resiliencia como una capacidad omnipresente y holística al 'abarcar todo' —la que genera” en los individuos la percepción de enfrentar un problema de gran amplitud.

Por otra parte, la oportunidad provista por la resiliencia descansa en la capacidad de aprovechar los conceptos y la terminología comunes para, posteriormente, plantear el juego en distintos ámbitos analíticos, desde la sociedad hasta el individuo. De manera simultánea, existe un proceso de comparación entre los múltiples niveles de resistencia y el riesgo genérico inherente al proceso de gestión. Los principios son los mismos, pero la aplicación y el alcance están en función de los cambios (ya sean inducidos o fortuitos) para toda la empresa.

En consecuencia, la organización resiliente presenta dentro de su inventario de capacidades estratégicas un diverso y complejo conjunto de formas múltiples tendientes a la aplicación rápida, flexible y ágil, de un comportamiento dinámico. Estos atributos de la organización comparten raíces comunes y están construidos a partir de los recursos complementarios, las capacidades y las competencias.

De manera concomitante con la agilidad estratégica se presenta la capacidad de resistencia o recuperación en las organizaciones y, así, éstas consiguen estar preparadas para enfrentar las condiciones cambiantes de su entorno. Como resultado de este hecho ellas podrán restaurar su vitalidad después de sufrir sacudidas traumáticas y emerger con 
un mayor grado de eficiencia, como resultado de la experiencia obtenida (Nemeth et al., 2009:39).

Las organizaciones con un mayor grado de flexibilidad y resiliencia, a diferencia de aquellas menos resistentes, en opinión de McManus et al. (2007), son las que:

1. Tienen un ethos organizacional de esfuerzo constante orientado a generar una mayor resistencia a las catástrofes.

2. Presentan un buen conocimiento de la situación, de las amenazas y oportunidades enfrentadas por la organización, a través del seguimiento activo de las señales fuertes y débiles provenientes del contexto.

3. Poseen un fuerte compromiso encaminado a la identificación proactiva y la gestión de las vulnerabilidades clave.

4. Presentan una cultura promotora de sus capacidades de adaptación, agilidad e innovación dentro de la organización.

Además, es importante reconocer (metafóricamente hablando) en cada organización la presencia de su propia "tormenta perfecta" —una combinación de hechos o circunstancias con el potencial de llevar a esa organización a una situación riesgosa-. Por ejemplo, la peor pesadilla para cualquier sistema financiero es la repentina pérdida de confianza por parte de los clientes, lo que crearía una "bola de nieve" con una trayectoria final en los bancos otorgantes de crédito. Para otras organizaciones puede ser el incumplimiento de un proveedor clave, la contaminación de la línea de producción en una fábrica de alimentos, un empleado que ocasione algún desperfecto intencional en las instalaciones de la compañía porque se encuentra descontento por alguna situación laboral, entre otros.

La presencia de estos hechos incrementa la vulnerabilidad del mundo organizacional, pues se encuentra conectado con el surgimiento de una disrupción y en una conceptualización amplia no se limita simplemente a operaciones realizadas en la cadena de suministro. Los efectos provocados se perciben tanto en los proveedores como en los clientes. Esta situación afecta a cualquier negocio, sobre todo si posee un alto grado de dependencia con una red confiable de comunicación global.

Otro factor que contribuye al aumento de vulnerabilidad de las organizaciones es su entorno competitivo, sobre todo en aquellas con operaciones ligadas a los procesos de 
globalización (Clegg, 2007:133-69; Porras, 2007:227-266); debido, fundamentalmente, a la velocidad de circulación del conocimiento en todo el mundo, lo cual dificulta mantener una ventaja competitiva basada en la tecnología o el know-how. Consecuentemente, muchos productos derivados de ambos factores de competencia se venden como mercancías y poseen características similares, aunque ahora los compradores basan su decisión de compra principalmente en los precios cada vez más bajos.

La existencia de una competencia cada vez más intensa no se traduce en mejores opciones para los consumidores, ni en el incremento de la intensidad de trabajo de las empresas, pero, en el mundo real, cuando una empresa fracasa por alguna razón, otras están esperando para tomar su lugar. Por esta causa las empresas deben ser más resistentes y colocarse por encima de sus competidores. Las empresas, razonablemente, tienden a invertir en la creación de capacidades orientadas a la recuperación rápida después de enfrentar cualquier tipo de disrupción y asegurarse simultáneamente de no haber causado la más mínima afectación en los intereses de sus clientes.

¿Cómo se emplea la resiliencia en las organizaciones? En esta sección se analiza el uso dado por las organizaciones al concepto de resiliencia. Con mucha frecuencia, las organizaciones frente a la incertidumbre y las crisis han buscado alternativas más o menos efectivas para transitarlas. Pero, algunas crisis se tornan emblemáticas ya sea por sus efectos, su amplitud o su agudización. Sobre todo, como se mencionó en párrafos anteriores, porque ponen en peligro la viabilidad futura de una organización. Como consecuencia de este hecho, la resiliencia se puede encuadrar dentro de los procesos estratégicos de una organización.

Por esta última razón, las organizaciones en la actualidad indagan y se acercan al concepto de resiliencia en búsqueda de algunas claves para prever y superar los momentos de crisis para alcanzar un mayor grado de efectividad (Bozz Allen, 2004:1-4). En esa búsqueda se han acercado a disciplinas como la ecología, la antropología, la lingüística, la psiquiatría, entre otras. Aunque la resiliencia asimilada por las ciencias sociales supone dos momentos: 1) el tránsito del trauma, es decir, la capacidad de pasar el momento crítico, y 2) salir mediante un proceso de reconstrucción hacia una nueva realidad.

Respecto a las disrupciones como elementos precursores de los procesos resilientes se pueden dividir en tres categorías, en función de su probabilidad de ocurrencia: 1) desastres naturales, 2) accidentes, y 3) ataques intencionales (gráfica 1). Estas categorías difieren en el papel desempeñado por los seres humanos y los factores causales 
aleatorios involucrados en ellas. En consecuencia el método de estimación probabilística también será diferente. En el caso de las organizaciones, según Sheffi (2007:65), el modelo de un perfil cifrado en el desarrollo hipotético de una disrupción se encuentra dividido en ocho etapas: 1) la preparación, 2) el evento disruptivo, 3) la primera respuesta, 4) el retraso en el impacto, 5) el impacto total, 6) preparando la recuperación, 7) la recuperación, y 8) el impacto a largo plazo.

Aunque es pertinente resaltar la naturaleza diferencial inherente a las disrupciones, porque nunca se presentan de manera idéntica en cada organización. A continuación se revisan de manera sintética cada una de estas etapas.

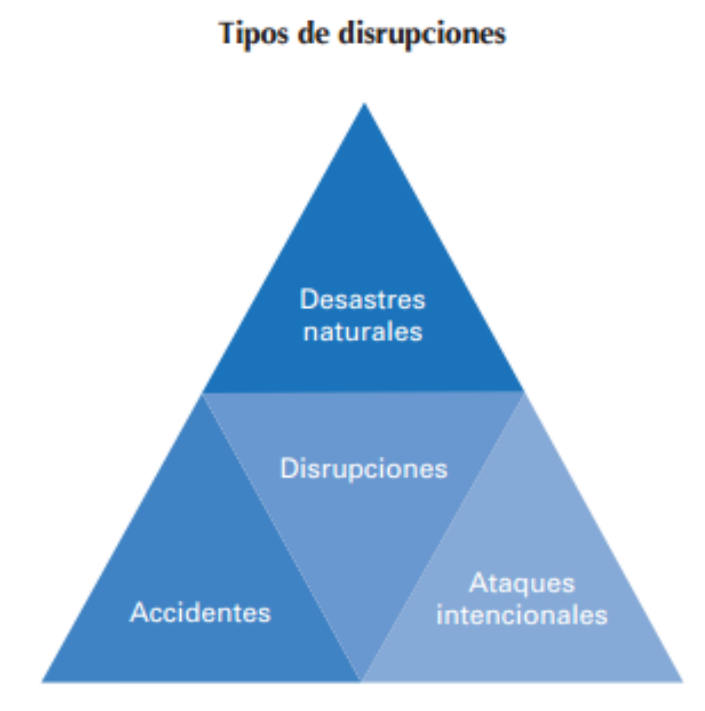

Fuente: elaboración propia con datos de Sheffi (2007:45).

1. La preparación. En algunos casos una compañía puede prever y prepararse para minimizar los efectos posteriores a la disrupción.

2. El evento disruptivo. Es el momento en el cual un tornado se desata, un accidente ocurre, una bomba explota, un proveedor se va del negocio, el sindicato emplaza a huelga o cualquier otra disrupción caracterizada por generar un alto impacto y tener una baja probabilidad de ocurrencia.

3. La primera respuesta. Después de que se presenta el evento disruptivo, el primer momento en un caso de incidente físico corresponde al equipo de respuesta inmediata (policía, bomberos, paramédicos), quienes deben atender el daño inicial. La duración de esta fase dependerá de la naturaleza del evento, desde apagar el fuego en caso de un incendio hasta meses para desmantelar, limpiar y volver a 
levantar lo destruido. En otro tipo de disrupciones, como aquellas que se refieren a acciones de tipo laboral o de tecnología de la información, la primera respuesta se dirige a evitar daños físicos y personas heridas. Esto implica, en ocasiones, detener los procesos y verificar la ausencia de daños físicos para la planta, el equipo o el personal.

4. El retraso en el impacto. El impacto total de algunas disrupciones se siente de inmediato, pero otras pueden tomar algún tiempo antes de afectar a una organización; depende de factores como la magnitud de la disrupción, la capacidad y preparación, la resiliencia inherente a la firma, y la cadena de suministros.

5. El impacto total. En algunas ocasiones, una vez recibido el impacto total de la disrupción el rendimiento cae estrepitosamente. En otros eventos, cuando la disrupción golpea directamente las instalaciones de una organización, el impacto total es inmediato.

6. Preparando la recuperación. Este momento inicia de manera inmediata o de forma paralela con la primera respuesta. En el ámbito empresarial esto puede ser ejemplificado con la evaluación de nuevos proveedores o el redireccionamiento de los recursos destinados a los antiguos si éstos últimos sufrieron algún desperfecto 0 accidente.

7. La recuperación. Reestablecer la producción o la distribución de los proveedores o hacer llegar de nuevo los productos a los clientes, reparar la infraestructura dañada o corregir los daños sufridos en las tecnologías de la información puede consumir un tiempo considerable. Para regresar a la normalidad en las operaciones algunas compañías aumentan la jornada laboral (tiempo extra), contratan más personas, buscan compañías maquiladoras, entre otras estrategias.

8. El impacto a largo plazo. Generalmente tomará algún tiempo recuperarse de los efectos provocados por una disrupción. Pero esta circunstancia se agudizará si la relación con los clientes se vio afectada en el proceso, en este caso el impacto será de larga duración y difícil enmienda.

Por otra parte, los riesgos son inmanentes a toda organización, incluso la resiliente, porque se pueden presentar en una sola unidad de negocio o en un proyecto único. En el caso de la organización resiliente el "truco" consiste en la definición del marco de referencia, 
construido a partir del planteamiento de las preguntas adecuadas, a fin de obtener las respuestas de interés acordes con el problema real al cual se hace frente.

En suma, con esta herramienta las organizaciones buscan prevenir y enfocarse en la selección de la estrategia más adecuada para responder a las crisis. Con toda esta información se detecta las vulnerabilidades con las cuales construye escenarios probables (Marcos y Macaulay, 2009) y los emplea en sus programas de capacitación.

De igual forma, la administración del riesgo a largo plazo no es una actividad independiente. Esta capacidad institucional se construye día a día a través de: 1) la cultura de la firma, y 2) las operaciones del negocio. Esta capacidad proveniente de la resiliencia empresarial otorga a las compañías la posibilidad de monitorear no sólo el rango total de riesgos tradicionales, sino los riesgos derivados del manejo de los ingresos o el efectivo y de los valores de la firma.

Como se ha podido observar a lo largo del artículo, el concepto resiliencia ha sufrido múltiples cambios al paso del tiempo y se ha enriquecido con nuevas definiciones, dependiendo del ámbito científico en el cual se le emplee. Después se integra al ámbito de la teoría organizacional y, en particular, se inscribe como un mecanismo detonador de procesos de previsión y planeación dentro de las organizaciones. Sobre todo en el horizonte estratégico de largo plazo, a fin de garantizar la sobrevivencia de la organización.

Por otra parte, la resiliencia ha permeado todos los ámbitos y niveles de la organización, desde el individuo hasta la sociedad. En este recorrido ha transformado el rostro organizacional transfiriendo las siguientes características a la organización resiliente: tiene un ethos organizacional de esfuerzo constante, orientado a generar una mayor resistencia a las catástrofes; presenta un buen conocimiento de la situación, de las amenazas y oportunidades enfrentadas por la organización por medio del seguimiento activo de las señales fuertes y débiles provenientes del contexto; posee un fuerte compromiso hacia la identificación proactiva y la gestión de las vulnerabilidades clave y presenta una cultura promotora de sus capacidades de adaptación, agilidad e innovación.

Al contar con estas características, las organizaciones resilientes se han encontrado mejor preparadas con un conjunto de estrategias correctas para enfrentar y superar las crisis. El ardid para interrogar al contexto (interno y externo) consiste en definir un marco de referencia construido a partir del planteamiento de las preguntas adecuadas, a fin de obtener las respuestas de interés acordes con el problema real. 
En suma, la resiliencia y sus aplicaciones organizacionales abren un nuevo sendero analítico para el estratega porque amplía los elementos de diagnóstico y permite construir una "batería" de escenarios y de planes alternos factibles mucho antes de la ocurrencia del hecho crítico.

La diferencia del enfoque resiliente respecto a las visiones estratégicas tradicionales consiste en el reconocimiento de los elementos necesarios para anticipar los efectos no deseados y atenuar las consecuencias del evento disruptivo mediante un ejercicio de aprendizaje aplicado de manera inmediata (ver Dixon, 2000). Por otra parte, los escenarios estratégicos típicos se concentran en la plausibilidad y la consistencia interna (Heijden, 1998:215), y en menor grado sobre los procesos de retroalimentación encaminados a la corrección de la contingencia.

Finalmente, se debe advertir al lector sobre la resiliencia y sus aplicaciones organizacionales se deben tomar las mismas precauciones empleadas al aplicar cualquier otra herramienta administrativa. Se requiere la autorización y el compromiso de la máxima autoridad jerárquica, infraestructura y recursos de toda índole para apoyar la aplicación de la herramienta (en un amplio sentido como capacidad, proceso, detonante), madurez de los integrantes y conocimiento de ellos sobre el tema. ${ }^{1}$

\section{Resiliencia: otra perspectiva de las experiencias sociales y personales dentro}

\section{de la empresa}

Generalmente cuando se aborda el tema de las crisis en las empresas nos referimos a sus resultados finales en términos de mercado, de finanzas o de producción. No se estudian en profundidad los procesos, las decisiones y las conductas que obtuvieron los resultados.

Los comportamientos tanto colectivos como individuales que ayudaron a sortear la crisis y que en el fondo son los potenciadores de los resultados, generalmente pasan a un segundo plano.

Estos comportamientos humanos, en un medio como el colombiano caracterizado por dificultades sociales tales como el conflicto armado, el secuestro, los paros, el debilitado

\footnotetext{
${ }^{1}$ Medina Salgado Cesar, (2012) La Resiliencia y su Empleo en las Organizaciones, pp. 29 - 39.
} 
tejido social y la falta de cultura basada en la solidaridad y en la cooperación hacen que las respuestas de las empresas, de sus grupos humanos y en particular las individuales para sortear las crisis, conlleven un mayor grado de complejidad.

El desgaste en términos de calidad de vida, de estrés, de sacrificio familiar e incluso de seguridad personal, para sólo mencionar algunas características, hacen que nuestro medio demande unos comportamientos y procesos particulares para enfrentar no sólo las situaciones normales de la competencia empresarial, sino que también requiere esfuerzos adicionales y específicos para orientar los comportamientos humanos con el fin de vencer las dificultades y generar resultados.

La manera de interpretar las crisis y de responder a ellas es una fuente de construcción tanto individual como colectiva de la cual derívanse procesos de aprendizaje y fortalecimiento. Esta es la óptica de la resiliencia.

De la estrategia, la cultura y la estructura: Cualquiera que sea el resultado de una crisis aparecen preguntas orientadas a encontrar cuáles han sido las características y los comportamientos de los grupos humanos y de los individuos para enfrentar las dificultades y haber logrado salir adelante. Por defecto, cuáles son los comportamientos que facilitan la agudización de las crisis tanto individuales como grupales y que en muchas ocasiones llevan al fracaso.

Estas respuestas comienzan por la cultura y los valores que las empresas han definido. Una empresa que haya definido en función de la estrategia y de forma clara cuál es su sistema de valores y su cultura, y si estos han sido divulgados, compartidos e introyectados a toda la organización, tendrá una plataforma de comportamientos orientados a fortalecer los resultados y sobre todo a sortear las dificultades.

La cultura y los valores tienen una prueba de fuego en cada crisis de la empresa, no tanto cuando las cosas andan bien. Es claro que una empresa que privilegie marcos de comportamiento basados en la confianza, la cooperación y la transparencia tendrá un mayor repertorio de posibilidades de éxito.

Otras de las respuestas harán referencia a la alineación y sincronización organizacionales, al liderazgo, al trabajo en equipo, la comunicación y otros factores relacionados con los procesos organizacionales que son igualmente factores determinantes para que una empresa sea exitosa. 
Otras respuestas harán referencia al clima organizacional como el resultante de una serie de decisiones, hechos, políticas que facilitan que en un ambiente de trabajo basado en la participación, la solidaridad y el compromiso, se puedan sortear las crisis con mayor facilidad.

La resiliencia como una nueva perspectiva: Pero profundizando en los comportamientos organizacionales hay unas categorías de análisis que aparecen subyacentes y que han sido tratadas parcial o tangencialmente al analizar desde otras ópticas los procesos humanos que se dan dentro de las organizaciones.

Estas categorías deben dar alguna explicación del porqué unas organizaciones y unas personas dan respuestas positivas a pesar de las dificultades con una mayor facilidad y propiedad que otras. Del porqué algunas empresas y algunas personas resurgen de las dificultades fortalecidas y con una mayor contundencia en su accionar y resultados.

Edgar Schein habla de la supervivencia organizacional en términos de flexibilidad y adaptabilidad en los niveles grupales e individuales. Warren Benís habla desde la perspectiva de los ingredientes básicos del liderazgo de la visión, pasión, integridad, confianza, curiosidad y osadía. Carlos Devis y María Mercedes de Beltrán, autores colombianos, hablan desde otra perspectiva de la capacidad basada en la interpretación y orientación que cada individuo le puede dar a la crisis. Igualmente los estudios sobre el conflicto y su manejo han hecho importantes aportes al comportamiento humano enfrentando dificultades.

Lo novedoso del tema de la resiliencia radica en que es un enfoque multidisciplinario que busca integrar orientaciones y aportes de diferentes ciencias para establecer modelos de análisis, interpretación e intervención para lograr mejores resultados individuales y grupales en los diferentes contextos (educativo, empresarial, comunitario). De otra parte, el enfoque se hace desde la dinámica de los procesos que abordan los individuos o los grupos humanos para enfrentar las crisis.

Atributos de la resiliencia: Se han determinado por parte de algunos autores siete atributos o factores que caracterizan la resiliencia:

$\checkmark$ Introspección. La capacidad de autocrítica, es decir de observarse a sí mismo y al entorno, hacer cuestionamientos profundos y dar respuestas honestas. 
$\checkmark$ Independencia. La capacidad para ver objetivamente los problemas o las situaciones, establecer límites sin dejarse apasionar o influenciar por sus propios mapas.

$\checkmark$ Relación. La capacidad para brindar, sostener y establecer relaciones de confianza y solidaridad fuertes y de largo plazo con otras personas o grupos.

$\checkmark \quad$ Iniciativa. La capacidad para autoexigirse, apersonarse de su responsabilidad, de sus decisiones y consecuencias.

$\checkmark$ Humor. La capacidad de afrontar las situaciones en forma lúdica y divertida, encontrando en la crisis una fuente de inspiración.

$\checkmark$ Creatividad. La capacidad de establecer y crear orden y nuevos modelos a partir de la confusión.

$\checkmark$ Moralidad. Dar sentido trascendente a las actuaciones, dando y deseando a otros el bien propio.

Dentro de las investigaciones adelantadas se ha establecido que estos atributos o factores conforman al operar integradamente un sistema de protección que fortalece el análisis y la toma de decisiones (en el sentir, pensar y actuar) pero que sobre todo crea una plataforma o un mapa para enfrentar la crisis que se enriquece permanentemente.

La resiliencia entonces es la capacidad de los seres humanos para sobreponerse a las crisis y construir positivamente sobre ellas, basada en unos factores que facilitan y amplifican dicha respuesta. En otras palabras es el sistema que se desarrolla por parte de un individuo o un grupo para enfrentar efectivamente la adversidad.

En el lenguaje coloquial se habla de la "fortaleza interna" o de la "solidez por dentro", términos que sintetizan el tema.

Qué alternativas ofrece la perspectiva de la resiliencia: Es indudable que estamos ante un nuevo concepto para las ciencias administrativas aunque sus primeros desarrollos se han hecho en escenarios de tipo social o pedagógico. El concepto enriquece las discusiones desde la multidisciplinariedad o transdisciplinariedad de las ciencias sociales y económicas, en las cuales ya resulta prácticamente imposible establecer diferenciaciones o linderos sobre los objetos o sujetos de las mismas.

Antes por el contrario, al igual que en otras áreas del conocimiento como la programación neurolingüística, la convergencia y aportes de investigaciones de diferentes 
ciencias ayudan a enriquecer el conocimiento y las respuestas o resultados prácticos que éstas deben dar al estar al servicio del mejoramiento del hombre.

La resiliencia en los términos descritos provee una nueva fuente de conocimiento y práctica para entender y enfrentar ciertos procesos o eventos particulares de la vida empresarial, tales como:

$\checkmark$ Procesos de cambio organizacional y cultural, en los cuales se pone a prueba la capacidad tanto individual como grupal para enfrentar estos retos.

$\checkmark$ Procesos de compra, venta, fusión, en los cuales la confluencia, contradicción y dispersión de intereses personales y grupales se ponen a prueba.

$\checkmark$ Procesos de adaptación a demandas del mercado, que conlleven cambios en las prácticas tradicionales.

$\checkmark$ Procesos de reducción o de reasignación de personal. Aquí es importante destacar cómo algunas empresas consultoras de alguna manera han utilizado el concepto de resiliencia y sus atributos como marco de referencia, tanto en las intervenciones individuales como grupales en los procesos de outplacement o downsizing.

Es importante destacar que cuando se ha hablado de la adaptación al cambio, en la mayoría de los casos se ha visto desde la óptica exclusivamente de la empresa en cuanto al resultado que se busca. Desde la óptica del grupo o del individuo se han estudiado las consecuencias de la adaptación o no adaptación al cambio. La resiliencia y sus atributos pueden ser un insumo importante para hacer estos procesos menos traumáticos, más productivos y sobre todo para lograr respuestas y comportamientos que potencien y enriquezcan dichos procesos y terminar fortaleciendo tanto a la empresa como a sus colaboradores.

La resiliencia como una competencia: Dentro de la herramienta de manejo de competencias cabe preguntar si la resiliencia puede enmarcarse como una de ellas. Recurriendo al concepto de que competencias son aquellas habilidades y conductas medibles que son fuente de la excelencia y de la diferenciación, encontramos que en algunos de estos sistemas de competencias se identifica una denominada capacidad de recuperación. Es definida en términos de la capacidad de recuperarse rápidamente ante 
frustraciones o fracasos. Esta competencia es utilizada en ciertas áreas o procesos de las empresas como el comercial, en donde es un factor clave para la revitalización y motivación a la tarea y al resultado inmediato.

Los conceptos son aproximados ya que la persona con una alta resiliencia tendrá una mayor capacidad de recuperación. Sin embargo el escenario y el tiempo no permiten utilizar el término como una competencia dentro del marco conceptual del presente trabajo. Seguramente algunos de los factores o atributos de la resiliencia se han utilizado total o parcialmente como competencias, pero la conclusión es que la Resiliencia se estructura más como un proceso de crecimiento en construcciones de largo plazo y enfocado más hacia las estrategias que hacia la operación.

Algunos autores han utilizado el término como una competencia pero tiende a perder el vigor y significado que ha tenido en su elaboración inicial en las ciencias sociales.

En el plano empresarial encontramos otros ejemplos de cómo muchas empresas y comunidades han logrado superar con éxito sus dificultades y construir sobre ellas.

$\checkmark$ La resiliencia es una manera de ver los comportamientos humanos desde una perspectiva multidisciplinaria que tiene como objetivo mejorar los procesos y resultados de los grupos humanos frente a las crisis.

$\checkmark$ Trasciende el ámbito empresarial por su concepción holística que tiene su máxima posibilidad en los valores y cultura de la sociedad. Su utilización en los procesos de educación es de vital importancia para lograr mejoras en la calidad de vida familiar, social o empresarial.

$\checkmark$ En los escenarios de la empresa colombiana es una fuente de enriquecimiento del conocimiento y de las prácticas que puede contribuir a la superación de las crisis por las que pasan. ${ }^{2}$

\footnotetext{
${ }^{2}$ Atehortúa M. Miguel, (2000). Resiliencia: Otra Perspectiva de las Experiencias Sociales y Personales Dentro de la Empresa, pp. $47-55$.
} 


\section{MÉTODO Y MATERIAL}

En esta investigación, al identificar las dimensiones y sus indicadores relacionados con la resiliencia organizacional se está aportando conocimiento valioso sobre lo que identifica a una organización resiliente, para desarrollar una capacidad a partir del aprendizaje.

La investigación se fundamentó inicialmente en un tipo de estudio exploratorio donde se realizó una revisión bibliográfica especializada en el tema de resiliencia a través de la recopilación de datos que profundizan el tema en sus diferentes áreas, específicamente en el campo empresarial, esto permitió construir la matriz que identifica cuando una organización es resiliente, es impórtate resaltar que esta investigación es el primer paso para determinar si la matriz es funcional dentro de la investigación, para ello en futuras investigaciones se deberá implementar y hacer una análisis más descriptivo en el tipo de investigación, por esta razón el análisis que se hace en este artículo es de tipo documental y su validez se fundamenta en los datos recopilados a través de los diferentes autores que profundizan en el tema de resiliencia organizacional.

Para ello se tomó como base el diseño de investigación transeccional exploratorio, donde se abarcó el contexto de resiliencia desde sus diferentes autores, dando un concepto inicial para hallar un problema de investigación que pocos autores han profundizado en el campo organizacional que es identificar cuando una empresa es resiliente y como a través de la propuesta y la aplicación de una matriz esta organización capta y aprende su funcionalidad y así potencializa los logros y las buenas prácticas.

Esto se llevará a cabo a través de tres dimensiones que enmarcan el contexto de que es una organización, para lo cual serán mencionadas de la siguiente forma:

Iniciativa: fortalecer a las organizaciones para que puedan maximizar su capacidad operacional y estructural. Mutabilidad: capacidad que tiene un ser o una organización de cambiar su aspecto, su forma o sus características. Interacción: un proceso de gestión de cambio eficaz requiere preparación y un esfuerzo integral que implique a todos los niveles de la organización. Con las dimensiones anteriormente descritas se propondrán aquellos factores que contribuyen a la creación de resiliencia organizacional, identificando la manera de crear ventaja competitiva, entendiendo la forma de administrar las adversidades internas y externas, enfrentándolas, sobreponiéndolas y aprendiendo de ellas para fortalecerse a través del modelo de matriz I.M.I. todo esto de manera simultánea justifica el desarrollo de la presente investigación que se convertirá en un punto inicial para futuras investigaciones. 


\section{ANÁLISIS Y DISCUSIÓN DE RESULTADOS}

Identificación de los elementos de la resiliencia empresarial: La resiliencia en las organizaciones y/o empresas no solo busca hacerlas sobrevivir sino también prosperar en medio de la adversidad; a continuación se presentaran los indicadores propuestos que identificaran a una organización resiliente.

${ }^{3}$ Figura No. 1

\section{Indicadores de Resiliencia}

\section{Liderazgo}

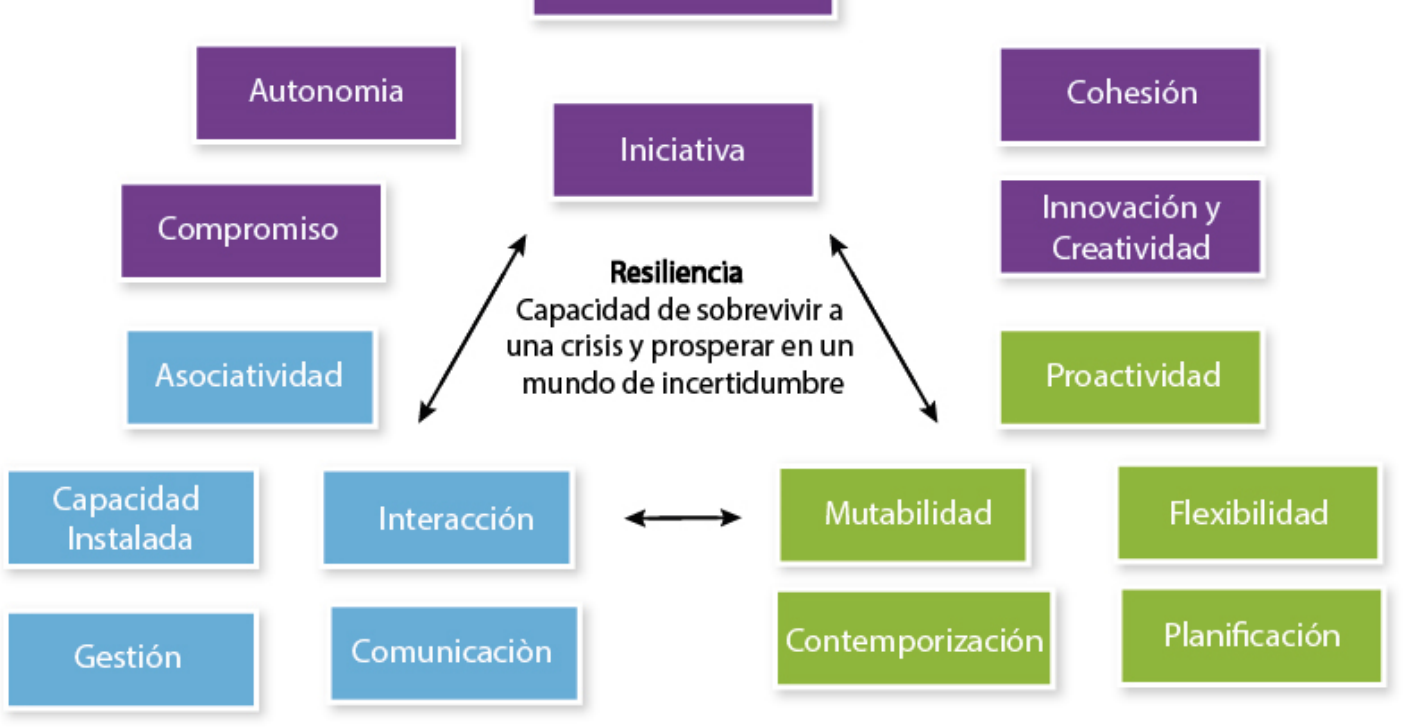

Se han identificado trece (13) indicadores que buscan evaluar la capacidad de recuperación de una organización (Resilient Organizations, 2012). Con los cuales se construye la matriz IMI a partir de la propuesta de los indicadores para la medición de procesos; se constituye en el aporte principal de la investigación y su diseño se apoyó a partir de los diferentes conceptos y artículos descritos para la investigación y en concordancia con los objetivos. El propósito de la investigación es ofrecer a la comunidad académica y empresarial un instrumento que permita hacer una medición de la gestión de

\footnotetext{
${ }^{3}$ Fuente: http://www.resorgs.org.nz/Content/what-is-organisational-resilience.html
} 
diferentes áreas de la organización y obtenga un resultado, cuyo análisis con la aplicación de las variables propuestas; establezca la situación de la empresa. La matriz en cuestión se diseñó para ser utilizada en las empresas que quieran medir la resiliencia, pero es aplicable a cualquier empresa que quiera evaluar su clima organizacional. La estructura de la matriz hace posible su aplicación, aunque es necesario, a juicio del autor, hacer ajustes puntuales al momento de su ejecución, dependiendo, entre otros factores, del tamaño de la empresa y/o el desarrollo del sector donde esta ópera.

Hoy más que nunca, la medición de los procesos que se hacen al interior de las diferentes áreas funcionales, permite mejores decisiones de recuperación por ello se describirán cada indicador y su aporte para la medición. En esta matriz estamos analizando la resiliencia dentro de tres grandes dimensiones: iniciativa, mutabilidad e interacción; las cuales se articulan y se aplican en el estudio de las relaciones de las organizaciones y su comportamiento. Cada una de estas dimensiones está conformada por una serie de indicadores que a su vez permiten tener datos cuantificables y puede determinar el nivel de resiliencia que tienen las organizaciones. A continuación se describirá cada indicador y el aporte dentro de la matriz.

El liderazgo "significa visión, estímulo para los demás, entusiasmo, amor, confianza, vigor, pasión, obsesión, consistencia, uso de símbolos, prestar atención. E liderazgo ha de estar presente en todos los niveles de la organización. ${ }^{4}$ El liderazgo conlleva un comportamiento determinado para influir en el comportamiento de otras personas; esto a su vez permite influir de manera directa ante las situaciones en donde se requiere de un mayor esfuerzo o capacidad ante las eventualidades. El liderazgo en la resiliencia juega un papel importante ya que con buenos líderes se puede llevar a cabo cualquier plan que permita subsanar cualquier percance que esté perjudicando la funcionalidad de la organización.

La cohesión es esencial para el desarrollo de un grupo, su trabajo, la unidad de esfuerzos en el logro de metas y objetivos comunes, al respecto Shaw en 1.983 resalta "Grupos con elevada cohesión se sienten más satisfechos". Un grupo alcanza lo que se propone cuando está cohesionado, de allí que la unidad de esfuerzos y objetivos comunes lo fortifica, le facilita sus logros y lo lleva a altos niveles de desarrollo, de manera que la cohesión es imprescindible, de ella depende la ponderación que tiene la membresía de su

\footnotetext{
${ }^{4}$ Peters, T. (1993): Reinventando la excelencia. El magenament liberador, Ed. B, Barcelona.
} 
imagen, su atractivo e incluso su fuerza de pertenencia o el deseo de mantenerse en él. ${ }^{5}$ La cohesión en los grupos se refiere a la solidaridad que existe entre los miembros de un grupo y la atracción que despierte la organización en el mismo. La cohesión dentro de los grupos de trabajo se define como la cooperación y apoyo, responsabilidades compartidas, respeto, confianza, cooperación, unidad, buena comunicación, orgullo por la membresía, y sinergia para el logro de metas y objetivos en base de en determinadas normas y principios compartidos por todos los miembros impactando en el clima organizacional. ${ }^{6}$ A su vez la cohesión dentro de la resiliencia permite el relacionamiento entre los diferentes individuos que integran la organización y cómo interactúan ante situaciones adversas como equipo de trabajo. Esto en pocas palabras hace parte fundamental del trabajo en equipo en busca del cumplimiento de los objetivos trazados.

La innovación y creatividad; La innovación se entiende como un proceso que convierte un problema o necesidad, en una solución o idea creativa. La organización innovadora se caracteriza por su capacidad para canalizar las aportaciones creativas hasta convertirlas en resultados útiles para el mercado, o bien mejorar la calidad o la productividad internas. La creatividad se entiende como la capacidad para combinar ideas o sistemas de una manera original o establecer asociaciones poco comunes entre las ideas. La organización que estimula la creatividad, desarrolla enfoques nuevos o soluciones singulares ante los problemas. ${ }^{7}$ Son elementos que han venido interactuando en el entorno empresarial desde hace mucho tiempo, pero que a medida que los mercados se hacen más competitivos se debe fortalecer los mismos. La innovación dentro de la resiliencia permite que se puedan generar nuevas oportunidades de cambio o de crecimiento en la organización. Por su parte la creatividad permite generar diferenciadores ante la competencia pudiendo manejar las adversidades del entorno.

La autonomía financiera es la capacidad que tiene una empresa de hacer frente por medios de financiación normal a su deudas exigibles. Se alcanza cuando nuestros Activos Productivos (AP) generan unos Ingresos Residuales (IR) superiores a nuestros Gastos (G). El ratio mide la autonomía o independencia financiera de la entidad. A través

\footnotetext{
5 Shaw, M.: (1983) Dinámica de Grupo. Psicología de la Conducta de los Pequeños Grupos. Edit. Herder. Barcelona.

${ }^{6}$ Chruden, Herbert J. (1977). "ADMINISTRACIÓN DEL PERSONAL”. Editorial Continental. Pp. 288-311

${ }^{7}$ Consultado en: http://www.uac.edu.co/images/stories/publicaciones/revistas_cientificas/dimension-

empresarial/volumen-11-no-1/articulo04.pdf
} 
del mismo se intenta conocer cuál es el nivel óptimo de endeudamiento de una empresa. La libertad financiera está íntimamente ligada a la solvencia entendida ésta en sentido amplio, es decir, como la garantía aportada por los activos y por la producción de flujos de tesorería para atender al costo de los recursos propios y ajenos, y al reintegro de estos últimos. ${ }^{8}$ Permite identificar por medio de la cadena de mando (de la empresa) el nivel de autonomía financiera y cómo esta se mantiene ante cualquier situación. Esto quiere decir que la parte financiera de una organización de forma directa impacta ante los hechos de resiliencia que se den en las organizaciones. Por eso la importancia de mantener un estricto control de efectivo lo que permite contar con los recursos necesarios cuando se presentan coyunturas que requieren de recursos económicos para cubrirlas.

El compromiso de las personas con la organización constituye un activo importante, puede ser uno de los mecanismos que tiene la dirección de recursos humanos para analizar la lealtad y vinculación de los empleados con su organización. Es por tanto, importante para las organizaciones conocer no sólo el tipo sino también el grado de compromiso de sus miembros. (Compromiso del Trabajador hacia su Organización y la relación con el Clima Organizacional..$^{9}$ De cada uno de los empleados en aspectos como tiempo de dedicación, actitud y remuneración juegan un papel fundamental al momento de presentarse resiliencia en la organización debido a que va ligado al liderazgo que puedan ejercer las cabezas de área ya que el compromiso (se da o) está ligado al ejemplo o cultura organizacional.

La asociatividad empresarial es un mecanismo mediante el cual las organizaciones unen voluntades, iniciativas y recursos, alrededor de objetivos comunes, con el propósito de ser más competitivas en el mercado global. (Rosales, 1997). Los procesos de asociatividad son reconocidos como mecanismos que posibilitan, entre otras cosas, la cooperación entre empresas con el fin de lograr ventajas tanto para ellas mismas como para el entorno en el cual se instauran. ${ }^{10} \mathrm{Se}$ busca identificar el nivel de asociación entre las diferentes áreas y ante situaciones adversas la toma de acciones que permitan cumplir con los objetivos de la empresa. En la resiliencia empresarial es importante la unión en

\footnotetext{
8 http://www.ief.es/documentos/recursos/estadisticas/estadisticas_tributarias/sociedades/93_Metod6.pdf

${ }^{9}$ Consultado en:

http://web.b.ebscohost.com.bdatos.usantotomas.edu.co:2048/ehost/pdfviewer/pdfviewer?sid=89834a763c3a-422c-8bdb-491fe6e41d47\%40sessionmgr114\&vid=58\&hid=124

${ }^{10}$ Rosales, H. (1997). La asociatividad como estrategia de sobrevivencia de las PYMES. Cambios estratégicos en las políticas industriales. En: Revista Capítulos 51, Caracas, Sela, Julio-Septiembre.
} 
busca de lograr los objetivos; esta asociatividad se ve reflejada en comportamiento entre individuos y también en las actividades.

Capacidad instalada Es la cantidad máxima de Bienes o servicios que pueden obtenerse de las plantas y equipos de una Empresa por unidad de tiempo, bajo condiciones tecnológicas dadas. Se puede medir en cantidad de bienes y servicios producidos por unidad de tiempo. La capacidad instalada es el potencial de producción o volumen máximo de producción que una empresa en particular, puede lograr durante un período de tiempo determinado, teniendo en cuenta todos los recursos que tienen disponibles, sea los equipos de producción, instalaciones, recursos humanos, tecnología, experiencia/conocimientos, etc. ${ }^{11}$ Esto permite saber en qué momentos se requiere de buscar apoyo adicional o por el contario cómo se puede optimizar los recursos y estos a su vez generen un ahorro para la organización en temas como tiempo de dedicación y desgaste de maquinaria.

La gestión, medida de proximidad a los resultados esperados y la adición del potencial humano a la ventaja competitiva de la organización son los ejes que orientan el proceso conocido como la «gestión» (Quinn, Farman, Thompson y McGrath, 2003; Ansoff y McDonnell, 1990). La gestión requiere entenderse como un proceso que existe explícita e implícitamente en la medida en que las estrategias y las medidas de logro de objetivos y metas han sido definidas, desde el corto hacia el largo plazo. Juega un papel fundamental ya que con ella se mejorara la productividad y la competitividad, la gestión dentro de la resiliencia busca que cada recurso o acción ejecutada sea acorde a las situaciones presentadas.

La comunicación en las organizaciones se considera importante, puesto que las personas, a través de aquélla, generan acuerdos y posibilidades para integrarse en grupos, transformar su entorno y lograr objetivos por medio del trabajo organizado (Sapir, 1949; Whorf, 1956; Bormann, 1985; Echeverría, 1994; Flores, 1994). Se puede decir que la comunicación es el eslabón que integra y da sentido a las partes del sistema; de manera que la unidad, armonía y secuencia de las actividades organizadas en un sistema se logran gracias a la comunicación, por lo que Rogers y Rogers (1980, p.52) la consideran como el

“...elemento esencial en un sistema que une las partes o subsistemas para facilitar su interdependencia.” De hecho Rogers y Rogers (1980, p.7) manifiestan que es: “... el fluido vital de una organización". Entonces a la comunicación se le considera esencial para los 
sistemas, debido a que sin ésta la actividad organizada de aquéllos no podría llevarse a cabo. Mediante ella se cohesionan las funciones administrativas y se llevan a cabo actividades como selección de personal. Además, la función efectiva del liderazgo depende de una buena comunicación, porque a través de ella se informa, se incentiva al personal para el logro de los objetivos, se crea un ambiente armónico y, cuando es necesario, se plantean los cambios que requiere la organización. ${ }^{12}$ Que juega un rol muy importante en todas las etapas de resiliencia; (porque esta a su vez), se tiene que dar de forma asertiva y clara ya que permite que todas las acciones o instrucciones lleguen de una mejor forma y no se presenten discrepancias entre los individuos y diferentes áreas. Esto va muy ligado a llevar a un buen equipo de trabajo por el mejor camino.

La flexibilidad organizacional se define como la capacidad de respuesta de la empresa para adaptarse o para anticiparse a los continuos cambios que afectan a las empresas y organizaciones (Volverda, 1998). Esta flexibilidad se sustenta en que la organización cuenta con límites definidos normalmente de forma rígida que han de permeabilizarse en sus niveles jerárquicos, entre funciones y puestos de trabajo. La flexibilidad organizacional está muy relacionada con la innovación y con el éxito competitivo (Díez de Castro et al., 2002). ${ }^{13}$ Busca ajustarse de acuerdo a las necesidades del entorno y por medio del resultado desarrollar recursos que se encontraban latentes y que la empresa desconocía hasta el momento. El término flexibilidad también nos permite ajustarnos ante cualquier eventualidad buscando ajustar o reorganizar los recursos físicos y económicos. Se define como la capacidad de respuesta rápida, eficiente y variada para adaptarse y/o anticiparse a los distintos tipos de cambio que continuamente están afectando a la organizaciones debido a la evaluación de sus circunstancias internas y externas, lo cual desarrolla o mantiene (entendiendo de esta forma) la ventaja competitiva, hace referencia a las habilidades de la organización para responder de forma adecuada y en el momento preciso a los cambios del entorno que puedan afectar significativamente a los resultados empresariales.

\footnotetext{
${ }^{12}$ Consultado en: http://web.b.ebscohost.com.bdatos.usantotomas.edu.co:2048/ehost/pdfviewer/pdfviewer?sid=89834a76-3c3a422c-8bdb-491fe6e41d47\%40sessionmgr114\&vid=94\&hid=124

13 Revista Problemas del Desarrollo, 183 (46), octubre-diciembre 2015165 Ventajas competitivas de la flexibilidad
} 
La proactividad; Ser dinámico, energético, pulsar la alacridad y ser autoestimativo, tomar la iniciativa, en consecuencia, ser el motor impulsor de los acontecimientos y hacer que las cosas sucedan Ser proactivo involucra por cierto la "elasticidad" y me refiero a la capacidad de comprender, de tolerar, de respetar las ideas muchas veces no coincidentes con nuestros tradicionales paradigmas y así, aprender y aprehender nuevas formas., no solo será gravitantemente positivo para el desarrollo de la persona como persona, sino para la organización y rendimiento empresarial o productividad. La conducta proactiva anticipa consecuencias futuras de las acciones presentes, asumiendo la incertidumbre de esas consecuencias. Es por lo tanto una estrategia a largo plazo, poco constreñida por el entorno, que incrementa las probabilidades de acercarse a las metas esperadas en el trabajo, haciendo el puesto de trabajo más interesante y controlable (Crant, 2000; Frese y Fay, 2001). Identifica cómo los empleados, de acuerdo a su nivel de responsabilidad y objetivos, aportan al proceso ejecutado y se hacen partícipes en la generación de ideas que contribuyan aportar de una forma positiva a las situaciones o momentos que lo requiera. La proactividad no significa sólo tomar la iniciativa, sino asumir la responsabilidad de hacer que las cosas sucedan; decidir en cada momento lo que quiere hacerse y cómo se va a realizar. En otras palabras, el directivo con personalidad proactiva cree que la persona diseña su propio entorno y destino.

La contemporización en la organización los conflictos se deben reducir; se está de acuerdo en que se deben manejar los conflictos apropiadamente para lograr que se reduzcan los efectos negativos y obtener soluciones funcionales que permitan a los grupos alcanzar sus metas y objetivos. Contemporización este es un método que no permite ganadores y perdedores, sino que lleva más bien a negociar soluciones mutuamente satisfactorias a través de la renuncia o concesión de parte de los intereses de cada una de las partes en conflicto. Aunque el propósito es ganar-ganar, es una técnica difícil, porque las partes en conflicto pocas veces quedan plenamente satisfechas y muchas veces el conflicto que generó la situación de contemporización tiende a repetirse. No obstante, es una de las estrategias de resolución más recomendables. ${ }^{14}$ La contemporización identifica cómo la empresa se adapta a las diferentes situaciones buscando el cumplimiento de objetivos y el respeto e interés mutuo. (Internamente). La capacidad de estimular el trabajo en equipo y, la habilidad para manejar asertivamente los conflictos se generan en distintos

${ }^{14}$ Consultado en: http://estalinbarragan.blogspot.com.co/ 
niveles de la estructura de la organización y/o entre los actores que la integran; se consideran como el conjunto de competencias claves para lograr realmente una comunicación organizacional efectiva.

La planificación constituye una función básica y punto de partida de la gestión. Se concibe como "un proceso continuo y sistemático en el que las personas toman decisiones sobre acciones futuras, sobre el respaldo que deben tener dichas acciones futuras y cómo evaluar y medir el éxito"15 La planificación, como se ha observado, requiere la capacidad de determinar, definir y estructurar el conjunto de acciones estratégicas, tácticas y operativas para el desempeño de la organización en el presente y en el futuro, en concordancia con su entorno, lo que obligatoriamente exige un examen continuo de los resultados obtenidos. La planificación permite medir el nivel de cumplimiento del plan de cada área y cómo esta tuvo reacción ante cada situación presentada. Este último indicador es base fundamental de cualquier organización y es el centro para que los otros indicadores puedan interactuar entre sí. La planificación ayuda a una organización a trazar un rumbo para el logro de sus objetivos. El proceso se inicia con la revisión de las operaciones actuales de la organización y la identificación de lo que es necesario mejorar operativamente. A partir de ahí, la planificación implica el anticipar los resultados que la organización desea alcanzar y determinar las medidas necesarias para llegar al destino deseado.

Con cada uno de estos indicadores se busca tener una amplia información que permita determinar el nivel de resiliencia en la organización. Si bien es cierto estamos ante un mundo cambiante y que busca ajustarse ante cualquier situación positiva o negativa, de acuerdo al contexto donde se desarrolle. Esta matriz busca tener una perspectiva sobre como la resiliencia se está dando o abordando en las organizaciones.

Cada indicador está estructurado de tal forma que permita tener datos cuantificables y estos a su vez permitan entender o comprender cada uno de la mejor forma permitiendo tomar acciones o generar planes para que los niveles de resiliencia en la organización se mantengan de acuerdo la situación presentada. Para entender un poco más a fondo la aplicabilidad de la matriz a nivel organizacional podemos afirmar que cada uno de los indicadores hacer parte fundamental de un núcleo de funcionamiento en cualquier

15 Performance Strategies Inc. Performance Strategies Glossary. 1996. Disponible en: http://www.perfstrat.com/articles/spgloss.asp [Consultado: 20 de mayo de 1999]. 
organización. Los resultados de cada indicador se trabajan de forma independiente para luego pasar hacer una unificación de los mismos y así obtener una visión general del estado de resiliencia en las organizaciones. A partir de la descripción de cada uno de los indicadores descritos anteriormente se proponen las variables con la cual permite hacer un análisis e interpretación.

\section{Análisis e Interpretación de las variables}

Para el liderazgo y la gestión se propone El proceso de evaluación de desempeño que implica un conjunto de elementos y subprocesos que van más allá de la sola medición. De hecho, es pertinente cubrir tres aspectos fundamentales: la identificación del rendimiento que será evaluado, la medición de los resultados y la gestión de las conclusiones del estudio. Porque el éxito de toda organización depende del desempeño de las personas, y mientras se mida y evalúe este desempeño, se podrán emprender acciones orientadas a obtener resultados positivos. No obstante, para que esto sea así, es imprescindible realizar la evaluación de desempeño de la manera más adecuada posible, lo que se materializa cumpliendo los siguientes pasos: identificar los problemas relacionados con el desempeño, ofrecer a los trabajadores información constructiva y emprender acciones para mejorarlo. El factor de éxito en la implantación de un proceso de evaluación de rendimiento es la comunicación. En particular, aconseja documentar el desempeño de los trabajadores durante el período de evaluación, dar lugar a las perspectivas de los trabajadores en el proceso y poner énfasis en el comportamiento y no los rasgos personales del personal evaluado. ${ }^{16}$

Para la cohesión, el compromiso, la flexibilidad y la contemporización se propone el Diferencial Semántico (Osgood) permite medir la significación que tienen ciertos objetos o situaciones para las personas a las cuales se le aplica. La significación se determina mediante la ubicación del objeto elegido en un "espacio semántico" definido por una gran cantidad de adjetivos extremos. La escala final se califica sumando las puntuaciones obtenidas respecto a cada item o par de adjetivos. Uno de los métodos consiste en el cálculo de los valores totales que la persona otorgó a cada concepto. ${ }^{17}$

\footnotetext{
${ }^{16}$ Alejandra González Mármol Debates IESA. abr-jun2010, Vol. 15 Issue 2, p9-10. 2p.

17 Consultado en: https://sites.google.com/site/tecnicasdeinvestigaciond38/estadistica-para-las-ciencias-delcomportamiento/2-3-diferencial-semantico
} 
Para la innovación y la creatividad se propone la variable Costo-Beneficio de la innovación. Este indicador es del tipo "Economía", y se basa en la cuantificación monetaria de los recursos utilizados en llevar a cabo innovaciones a cierto proceso, en relación a los beneficios económicos obtenidos por su implementación. Es importante tener presente que además de los ingresos económicos que se pueden desprender de la innovación, se tienen otros beneficios intangibles que no son considerados en el cálculo. ${ }^{18}$

La variable para la autonomía se propone autonomía= patrimonio neto / activos totales. Un índice elevado indicaría fuerte capacidad de solvencia y una mejor defensa en épocas de crisis económica, al poder actuar los recursos propios como absorbentes de las pérdidas; sin embargo, un exceso de capitales podría actuar negativamente sobre la rentabilidad de los accionistas si hubiese otras opciones de financiación con un coste menor. Un ratio reducido supone que una parte importante del activo está atendida con créditos. Ello podría significar dificultades para atender el pago de las deudas. En periodos económicos difíciles no existiría la posibilidad de compensar pérdidas con recursos propios y podrían situar a la empresa cerca de la insolvencia o de la reconversión. En empresas con una tasa de cobertura débil, en épocas de recesión económica, la probabilidad de insolvencia se acentúa. Una empresa altamente endeudada, si se enfrenta a una contracción de la demanda y a resultados negativos, podría llegar a una situación financiera límite. ${ }^{19}$

La asociatividad se puede medir mediante la variable del método mactor. El método de análisis de juego de actores, Mactor busca valorar las relaciones de fuerza entre los actores y estudiar sus convergencias y divergencias con respecto a un cierto número de posturas y de objetivos asociados. A partir de este análisis, el objetivo de la utilización del método Mactor es el de facilitar a un actor una ayuda para la decisión de la puesta en marcha de su política de alianzas y de conflictos. ${ }^{20}$

\footnotetext{
${ }^{18}$ http://www3.upc.edu.pe/bolsongei/bol/29/737/javier_bermudez1_cuadernos_de_investigacion.pdf

19 Consultado en: http://www.eumed.net/librosgratis/2009c/581/Ratio\%20de\%20cobertura\%20del\%20activo\%20total\%20por\%20capitales\%20propios.htm

${ }^{20}$ http://es.laprospective.fr/Metodos-de-prospectiva/Los-programas/68-Mactor.html
} 
La capacidad instalada se propone la variable Cantidad de Activos en uso / Cantidad de Activos existente o disponible. En términos de la industria manufacturera en general, la capacidad instalada se refiere al volumen de producción que se puede obtener con los recursos disponibles de una compañía en determinado momento (recursos como dinero, equipos, personal, instalaciones, etc). La manera de obtenerla es calcular cuántas unidades de producto puede la empresa fabricar por hora, y multiplicar eso por las horas laborables disponibles. Normalmente se calcula por familia de productos, ya que son los que comparten un proceso similar y nos puede dar una tasa de producción promedio. Por ejemplo, si habláramos de una máquina que puede producir 100 piezas por hora y que la empresa trabaja 8 horas al día, 5 días a la semana, hablaríamos de una capacidad instalada de: 100 * $8 * 5=4,000$ piezas a la semana. Normalmente, como la producción en piezas es muy subjetiva, se manejan unidades como toneladas que se pueden procesar por unidad de tiempo. ${ }^{21}$

La comunicación Cantidad de canales de comunicación usados / cantidad de canales de comunicación disponible. Se puede crear una medición de atributos asociados para una mayor profundización del concepto se propone varios indicadores:

Indicadores de Calidad percibida: Son aquellos que permiten establecer la dimensión de los atributos más importantes de cada uno de los canales y escenarios de interna utilizados por la compañía, determinada por la valoración de los mismos de acuerdo con el criterio expresado por los públicos que son impactados. Se obtienen a través de encuestas aplicadas a muestras representativas de la población, preferiblemente formuladas en escala Likert. Genera indicadores del tipo \% de empleados que considera útil la información divulgada en la Intranet.

Indicadores de Lecturabilidad: Son aquellos que permiten establecer los niveles de lecturabilidad general de cada una de las formas de comunicación, de modo que pueda compararse el desempeño de cada uno de ellos. Genera indicadores del tipo \% de empleados que lee habitualmente la sección Consejos útiles del boletín ABC

Indicadores de Proceso: Son aquellos que permiten establecer el comportamiento de las variables asociadas a la cantidad de acciones comunicativas desplegadas en cada caso Genera indicadores del tipo Costo por empleado del boletín ABC

\footnotetext{
${ }^{21}$ Consultar en: https://mx.answers.yahoo.com/question/index?qid=20061103082917AAmpMha
} 
Indicadores de despliegue argumental: Son aquellos que establecen la cantidad de información que ha sido divulgada sobre cada una de las variables o dimensiones que integran los componentes estratégicos de la comunicación en la empresa, a saber, su Identidad, su reputación y su cultura organizacional. Genera indicadores del tipo \% de temas divulgados asociados al atributo calidad de servicio.

Indicadores de relevancia de la línea argumental: Son aquellos que permiten determinar qué tan importantes y útiles son los diferentes contenidos que la organización divulga a través de toda su plataforma mediática. Genera indicadores del tipo \% de empleados que considera importante o muy importante los temas asociados a nuevos productos y servicios Indicadores de dominancia de los hábitos comunicacionales: Son aquellos que permiten establecer cuáles son las conductas más frecuentes que las audiencias asumen frente a cada uno de los medios que integran la plataforma mediática de la empresa. ${ }^{22}$

La proactividad se propone medir mediante preguntas dicotómicas: son reactivos que brindan sólo dos (2) alternativas de respuesta como son: verdadero-falso, sí-no, acuerdo, desacuerdo, presente-ausente, entre otras. Este tipo de pregunta, frecuentemente puede presentarse como pregunta de opción múltiple si se complementa con una alternativa neutral como: no opino, no sé, ambos o ninguno, no aplica, etc. ${ }^{23}$

Para la planificación la variable propuesta es la evaluación de gestión, entre los instrumentos que sirven para la evaluación de la gestión empresarial pueden mencionarse: las auditorías (externas, operativas o de controles internos), el tablero de control, el análisis de ratios. El objetivo de la evaluación de la gestión empresarial es medir lo actuado por el responsable directo de tomar decisiones en una empresa, la eficiencia y eficacia del empresario. Evaluar la gestión empresarial es examinar en forma integral la gestión de una empresa con el propósito de evaluar la eficiencia de sus resultados, teniendo en cuenta las metas y objetivos fijados, los recursos humanos, financieros y materiales empleados, la organización de esos recursos y los controles establecidos. ${ }^{24}$

Con la siguiente matriz se puede identificar si una empresa es resiliente.

\footnotetext{
Consultado en:

22 http://www.comunikandonos.com/medicion-de-la-comunicacion/251-como-se-mide-la-eficacia-de-loscanales-de-comunicacion-de-la-empresa

${ }^{23}$ http://servicio.bc.uc.edu.ve/educacion/revista/n36/art08.pdf

${ }^{24}$ http://admindeempresas.blogspot.com.co/2009/11/la-evaluacion-de-la-gestion-empresarial.html
} 
Tabla No. 1 Dimensiones para medir la resiliencia.

DIMENSION INDICADOR DESCRIPCION

Proceso que ayuda a dirigir y movilizar

VARIABLE

ANALISIS E INTERPRETACION personas $\mathrm{y} / \mathrm{o}$ ideas. Ejercicio de las cualidades de líder. Conlleva un comportamiento determinado para influir en el comportamiento de otras personas, o bien para cambiarlo cara a conseguir los objetivos de la organización entre los diferentes individuos que conforman las áreas funcionales de la empresa permitiendo potenciar y/o desarrollar capacidades.

Liderazgo

Evaluación de desempeño (Puntaje) El proceso de elementos y subprocesos que van más allá de la sola medición. De hecho, es pertinente cubrir tres aspectos fundamentales: la identificación de rendimiento que será evaluado, la medición de los resultados y la gestión de las conclusiones del estudio. Acción sistemática de evaluar la conducta y el trabajo de una persona con relación a sus responsabilidades. De acuerdo al método de medición se establece niveles de liderazgo y acciones tomadas ante los resultados manera:

Se plantea que un concepto adquiere significado cuando un signo (palabra) puede provocar la respuesta que está asociada al objeto que representa; es decir, se reacciona ante el objeto simbolizado. La técnica se desarrolla

Mide el nivel de relacionamiento que hay Índice de Cohesión: Provenientes de la aplicación entre los diferentes individuos que integran la de una escala diferencial semántico que permita

Cohesión adversas como equipo de trabajo (unión)

identificar actitudes y percepciones a partir de proponiendo una lista de adjetivos al sujeto, que él ha de relacionar con los conceptos propuestos. Los adjetivos se presentan en forma bipolar, mediando entre ambos extremos una serie de valores intermedios. Por ejemplo se presenta el par "justo" / "menos justo", separados por una especie de regla graduada en la que el sujeto debe marcar cómo ubica el concepto en relación con ambos polos. No se deben contraponer conceptos del tipo "bueno/malo" ya que la escala de medición del diferencial semántico es no comparativa, por lo que se debe bipolarizar siempre las preguntas en torno a mismo concepto. 
Son elementos que han venido interactuando en el entorno empresarial desde hace mucho tiempo, pero que a medida que los mercados se hacen más competitivos, dichos elementos han tomad un papel protagónico, ya que por medio de un papel protagónico, ya que por medio de éstos las organizaciones pueden desarrolla aquellas ventajas competitivas que les permitan mantenerse con éxito Son herramientas diferentes, pero que trabajan en conjunto para dar como resultado la generación de aquellos cambios dentro de la organización que conlleve una mayor satisfacción a sus clientes. Por esta razón, es importante que las empresas procuren una filosofía de gestión creativa e innovadora que les permita desarrollarse tanto vertical como horizontal, logrando una cadena de valor altamente competitiva y diferenciadora.

\section{Se busca medir:}

* La relación costo / beneficio del proceso de innovación * La relación entre las oportunidades de innovación y los colaboradores que participan en el proceso.

Beneficio $/$ Costo $=$ Innovación

* La relación entre las innovaciones generadas y el número de oportunidades de innovación identificadas.

* La relación entre las innovaciones llevadas a cabo sin éxito entre el total de innovaciones generadas.
Permite identificar por medio de la cadena de mando de la empresa el nivel de autonomía financiera y como esta se mantiene ante cualquier situación
Es una aproximación al nivel de autofinanciación de la Autonomía=Patrimonio Neto / Activos Totales empresa. Autonomía financiera que indica nivel de autofinanciación LIMITES: > 0,40 
Los resultados serán interpretados de la siguiente manera:

Ante situaciones que requieren mayor dedicación y esfuerzo por el equipo de trabajo, se busca identificar las situaciones

Compromiso el fin de establecer el nivel de compromiso de cada uno de los empleados en aspectos como tiempo de dedicación actitud y remuneración
Se plantea que un concepto adquiere significado cuando un signo (palabra) puede provocar la respuesta que está un signo (palabra) puede provocar la respuesta que está asociada al objeto que representa; es decir, se reacciona
ante el objeto simbolizado. La técnica se desarrolla proponiendo una lista de adjetivos al sujeto, que él ha de Indice de Compromiso: Provenientes de la relacionar con los conceptos propuestos. Los adjetivos quicación dorma bipolar, mediando entre ambos (a) partir de la aplicación de un instrumento (Puntos) perie de valores intermedios. Por ejemplo se presenta el par "justo" / "menos justo", separados por una especie de regla graduada en la que el sujeto debe marcar cómo ubica el concepto en relación con ambos polos. No se deben contraponer conceptos del tipo "bueno/malo" ya que la escala de medición del diferencial semántico es no comparativa, por lo que se debe bipolarizar siempre las preguntas en torno al mismo concepto.

Busca identificar el nivel de asociación entre las diferentes áreas $\mathrm{y}$ ante situaciones adversas la toma de acciones que permitan cumplir con los objetivos de la empresa. Esto

Asociatividad quiere decir que sin modificar la planeación quiere decir que sin modificar la planeación decisiones de acuerdo a los resultados de misma.
El método de análisis de juego de actores, Mactor busca valorar las relaciones de fuerza entre los actores y estudiar sus convergencias y divergencias con respecto a un cierto número de posturas y de objetivos asociados. A partir de este análisis, el objetivo de la utilización de método Mactor es el de facilitar a un actor una ayuda para la decisión de la puesta en marcha de su política de alianzas y de conflictos.

Buscar medir la capacidad de producción o

prestación de servicio y como esta puede

ajustarse ante cualquier situación sin ver

afectado el cumplimiento al cliente interno $y$

$\mathrm{Cl}:(1-\mathrm{CAU} / \mathrm{CAD})$

Cantidad de Activos en uso / Cantidad de Activos

Instalada externo 
Buscará mejorar la productividad y la competitividad de una organización. Identifica y hace referencia a las medidas $y$ estrategias llevadas a cabo con la finalidad

Gestión de que la empresa sea viable económicamente. Con funciones realizada por cada empleado de acuerdo a su grado de responsabilidad y participación dentro de la empresa y busca la forma de mantener un equipo de trabajo eficaz y eficiente
El proceso de evaluación de desempeño que implica un conjunto de elementos y subprocesos que van más allá de la sola medición. De hecho, es pertinente cubrir tres aspectos fundamentales: la identificación de rendimiento que será evaluado, la medición de los resultados y la gestión de las conclusiones del estudio. Se diseñada de acuerdo a la necesidad de la empresa. Directamente relacionado con el resultado final de a las evaluaciones de desempeño de empleados y empresarial esta última generalmente realizada una vez cada año.

dentifica los diferentes canales de

comunicación al interior de la empresa

mide el nivel de importancia que tiene cada uno buscando optimizarlos y fortalecerlos con el fin de usarlos según la necesidad y

Comunicación $=(\mathrm{CCCU} / \mathrm{CCCD})$

Cantidad de canales de comunicación usados / cantidad objetivos propuestos.

de canales de comunicación disponible. Se puede crear una medición de atributos asociados para una mayor profundización del concepto LIMITE: > 0,9

Busca identificar como la empresa a nivel operativo y administrativo puede ajustarse de acuerdo a las necesidades del entorno por medio del resultado desarrollar recursos que se encontraban latentes y que la empresa desconocía hasta el momento. (Externamente)
Índice de Flexibilidad (Puntos): Provenientes de a aplicación de una escala diferencial semántico e permita identificar actitudes y percepciones a partir de la aplicación de un instrumento
Los resultados serán interpretados de la siguiente manera:

Se plantea que un concepto adquiere significado cuando un signo (palabra) puede provocar la respuesta que está asociada al objeto que representa; es decir, se reacciona ante el objeto simbolizado. La técnica se desarrolla proponiendo una lista de adjetivos al sujeto, que él ha de relacionar con los conceptos propuestos. Los adjetivos se presentan en forma bipolar, mediando entre ambos extremos una serie de valores intermedios. Por ejemplo se presenta el par "justo" / "menos justo", separados por una especie de regla graduada en la que el sujeto debe marcar como ubica el concepto en relación con ambos polos. No se deben contraponer conceptos del tipo "bueno/malo" ya que la escala de medición del diferencial semántico es no comparativa, por lo que se debe bipolarizar siempre las preguntas en torno al mismo concepto. 
Por medio de una encuesta que incluye preguntas como:

¿Conoces tus fortalezas y debilidades?

¿Gestionas positivamente tus emociones?

¿Manifiestas tus opiniones de forma asertiva?

¿Confías en ti mismo y te gusta asumir retos?

¿Tomas la iniciativa y pasas a la acción?

¿Actúas con decisión para conseguir tus metas

¿Sueles transformar los problemas Identifica como los empleados de acuerdo a oportunidades para aprender y cambiar?

su nivel de responsabilidad y objetivos

aportan al proceso ejecutado y se hacen

participes en la generación de ideas que contribuyan de una forma positiva a las situaciones o momentos que lo requieran ¿Eres perseverante y concienzudo, y no te das
por vencidao ante la primera dificultad?

¿Asumes los fracasos?

¿Eres amoldable a las circunstancias y desafías lo tradicional por tus propias convicciones?

¿Eres inconformista y te esfuerzas siempre por mejorar todo lo que te rodea?

¿Eres un líder y aportas siempre algo positivo a las personas que te rodean?

$¿$ Tienes las agallas de asumir en cada momento lo que quieres hacer y cómo lo vas a hacer?

¿Asumes la responsabilidad de hacer que las cosas sucedan?

Puntos como sumatoria de los SI. en Se propone medir mediante preguntas dicotómicas: son reactivos que brindan sólo dos (2) alternativas de respuesta como son: verdadero-falso, sí-no, acuerdo, desacuerdo, presente-ausente, entre otras. Este tipo de pregunta, frecuentemente puede presentarse como pregunta de opción múliple si se complementa con una pregunta de opción múliple si se complementa con una alternativa neutral como: no opino, no sé, ambos o ninguno, no aplica, etc. Limite $>0,8$ 
Los resultados serán interpretados de la siguiente manera:

Se plantea que un concepto adquiere significado cuando un signo (palabra) puede provocar la respuesta que está asociada al objeto que representa; es decir, se reacciona ante el objeto simbolizado. La técnica se desarrolla Identifica como la empresa se adapta a las Índice de Contemporización (Puntos): proponiendo una lista de adjetivos al sujeto, que él ha de diferentes situaciones buscando el Provenientes de la aplicación de una escala relacionar con los conceptos propuestos. Los adjetivos Contemporización diferentes situaciones buscando el diferencial semántico que permita identificar se presentan en forma bipolar, mediando entre ambos cumplimiento de objetivos y buscando el actitudes y percepciones a partir de la aplicación extremos una serie de valores intermedios. Por ejemplo respeto e interés mutuo. (Internamente)

de un instrumento

Permite medir el nivel de cumplimiento de la planificación de cada área y como esta tuvo reacción ante cada situación presentada.
Evaluación de Gestión: Compromiso Vs Logros (Puntaje) se presenta el par "justo" / "menos justo", separados por una especie de regla graduada en la que el sujeto debe una especie de polos. No se deben contraponer conceptos del tipo polos. No se deben contraponer conceptos del tipo
"bueno/malo" ya que la escala de medición del "bueno/malo" ya que la escala de medición del debe bipolarizar siempre las preguntas en torno al mismo concepto.
Planificación
El proceso de evaluación de gestión: implica un conjunto de elementos y subprocesos que van más allá de la sola medición. De hecho, es pertinente cubrir tres aspectos fundamentales: la identificación del rendimiento que será evaluado, la medición de los resultados y la gestión de las conclusiones del estudio. Directamente relacionado con el resultado final de las evaluaciones de gestión de los empleados; generalmente realizada una vez cada año

Nota 1: Los conceptos que describen cada indicador son los referenciados dentro del análisis y discusión de resultados de la pag 30 a 36

Nota 2: La descripción de las variables son las referenciadas dentro del análisis e interpretación de las variables de la pag 37 ag 40

Fuente: tabla elaboración propia del autor del artículo 


\section{CONCLUSIONES}

Como resultado de la investigación presentada en este artículo, es posible concluir que la información recopilada es una visión no solo del concepto de resiliencia general, sino también del concepto de resiliencia desde diferentes disciplinas en el ámbito social, empresarial y organizacional; es aquí, donde el presente artículo desglosa a través diferentes autores que debe tener en cuenta los directivo de una organización para sobreponerse al caos y recuperase cuando identifica que su organización es resiliente. Para ello el articulo recopila datos tomados desde el punto de vista organizacional como un concepto relativamente nuevo que menciona las acciones de mejora que debe asumir las empresas resilientes y como sus colaboradores al enfrentarse al cambio inician una etapa de reconocimiento, compromiso y funcionamiento obligando a mejorar la operación interna o externa para tener una estabilidad más eficaz, es aquí donde el presente artículo esboza como se emplea la resiliencia a través de la existencia de distintos espacios en torno a la conceptualización de la resiliencia organizacional en tres pasos: la capacidad para prevenir, la capacidad de empeoramiento y la capacidad para recuperarse de las consecuencias negativas de un evento. El articulo también identifica que pasos debe tener la organización cuando es resiliente con cuatro diferenciadores que permiten evidenciar la resiliencia y como se emplean dentro de una organización.

Con la investigación anteriormente descrita se procedió a identificar indicadores que permitieran medir la resiliencia dentro de una organización, para ello se tomó como referencia algunos artículos que enfocan su trabajo a través de las experiencias sociales y personales dentro de la organización lo cual permitió identificar tres dimensiones globales presentes dentro de las organizaciones; la mano de obra, la infraestructura y la interacción tecnológica, con base en estas tres dimisiones se propuso gracias a la información recopilada trece indicadores que buscan evaluar la capacidad de recuperación de una organización a través del modelo Resilient Organizations del 2012 con lo cual fue construida la matriz IMI (Iniciativa, mutabilidad e interacción), esta matriz propone una acción a seguir luego de analizar un indicador con el propósito de ofrecer un instrumento de medición a través de una variable qué identifica cuando la organización es resiliente.

Este articulo buscar presentar y proponer elementos que permitan a través de una matriz (I.M.I.) realizar estudios posteriores donde al aplicarla logre identificar cuando una 
organización es resiliente, sus niveles de resiliencia y que acciones debe seguir la empresa con la información recopilada con las variables propuestas.

\section{RECOMENDACIONES}

Para la continuación y el fortalecimiento de la propuesta de la matriz IMI, se recomienda a futuros investigadores la complementación de otras dimensiones que permita identificar nuevos indicadores con sus respectivas variables y así analizar y abarcar todas las áreas de la organización entre ellas: producción, mercadotecnia, recursos humanos y finanzas, esto ayudará al fortalecimiento de la misma.

Otra recomendación sería identificar las posibles formas de medición y evaluación de esta matriz, para la obtención de resultados que sean cuantificables con la finalidad de medir el impacto y la eficacia de los programas de intervención, que permitan medir la evolución de los mismos y determinar si las acciones planeadas están obteniendo el resultado que permite identificar si una organización es resiliente.

\section{APÉNDICES}

\section{Casos y ejemplos de la aplicación de la resiliencia}

Para entender un poco en las empresas, como la capacidad de resistir las grandes presiones del mercado y de convertir la crisis en una oportunidad, en una compañía se logra a través de la gente. La resiliencia es una competencia que se puede aprender y hay otras que ayudan a hacerlo, como la autoconfianza, foco-resultados (enfocarse en los objetivos), perseverancia (no desfallecer) y flexibilidad (la capacidad de adaptarse a determinadas situaciones). Para dar mayor profundidad al tema de empresas resilientes se mostrara tres empresas en América Latina que se adaptaron a los cambios y que por sus estructuras y manejo de personal son claros ejemplos:

José cuervo México, desde hace más de 200 años, José Cuervo, la empresa más antigua de México y de América Latina, ha trabajado ininterrumpidamente en la consolidación de un prestigio fundado en la calidad de sus tequilas, que durante el siglo XX modernizo su industrialización y comercialización y posicionó esa bebida como referente 
de la cultura mexicana. Actualmente se vende en más de 90 países. José Cuervo Especial se dio a conocer a través de la muy famosa y mexicana bebida "Margarita".

José Cuervo se identifica que es una organización resiliente cuando tiene invadido el mercado mexicano de su producto, y se aproximó la nueva producción lo que implicó un alto depósito de mercancía en reserva (stock), lo cual conlleva a entrar en perdidas, afectando la disminución de sus ingresos totales; como resultado su utilidad neta se vio afectada de manera adversa.

Con los indiciadores de resiliencia propuestos en la matriz IMi se logran identificar los siguientes:

Liderazgo: aplicación de un plan Estratégico Global: Asegurar el liderazgo comercial de su marcas, la viabilidad económica de la empresa en el corto, mediano y largo plazo, asegurando una estable y bien remunerada fuente de empleos, una importante contribución económica para el campo, y un justo rendimiento para los accionistas.

Innovación y creatividad: Adopta bajo el enfoque Brand Company (Es una compañía que comercializa bajo identidad empresarial propia. Tiene su propio sello): comenzó a liderar y crear marcas y hábitos de consumo.

Capacidad instalada: Empresa que comenzó a integrar al 100\% en todas sus funciones: agrícola, comercial, institucional. Para la producción, comercialización y exportación del producto

Ha sabido aplicar una estrategia que otorga primordial papel al desarrollo de relaciones óptimas con sus clientes y proveedores mediante la aplicación de políticas que rescatan las habilidades de su capital humano, el que a su vez cuenta con políticas de motivación que van más allá del ámbito remunerativo pues sus trabajadores tienen incluso acceso a facilidades económicas para continuar con su capacitación y mejora de sus conocimientos.

Farmacias Ahumada Chile Farmacias Ahumada S.A., es la primera Cadena de Farmacias en Chile, con Farmacias en las principales ciudades del país. Es miembro de Walgreens Boots Alliance, la primera empresa global de salud y bienestar en el mundo, enfocada en el negocio de farmacias y grupo Internacional líder en el negocio de venta al público de productos de salud y belleza con orientación farmacéutica. La compañía emplea 
a más de 370.000 personas y tiene presencia en más de 25 países; es el Retail más grande de farmacias dedicado a la salud y diario vivir tano en EE.UU. como en Europa.

Se identifica resiliencia cuando Fasa entra en recesión esto hace que exista la disminución o pérdida generalizada de la actividad económica, con la cual se ha logrado mantener en el mercado de las farmacias ya que no existe ningún elemento diferenciador de la competencia, sus ventas comenzaron a caer notablemente afectando a toda la organización. Así que comenzó a imitar el modelo anglo-americano comenzó a ofrecer variedad de productos y bajo su propia marca así comenzó a enfrentar nuevos mercados.

Los indicadores identificados fueron:

Gestión: implementa una estrategia de expansión internacional manteniendo los mismos estándares de calidad en el servicio y de oferta que en las operaciones en Chile. Realizo una innovación constante en los servicios que presta y en las actividades operativas del negocio.

Compromiso: estructura la Coordinación de las actividades entre las sucursales de los países donde opera con estandarización de procesos.

El liderazgo: aplico una estructura matricial en la que la vicepresidencia ejecutiva está a cargo de la coordinación global y estratégica, así como de velar por el desarrollo de recursos humanos y transmitir sus valores y cultura.

Proactividad: los empleados en la Unidades de negocio trabajan de manera integrada, lo que permite estandarizar los sistemas operativos: tecnología, negociación regionales con proveedores multinacionales y compartir las mejores prácticas entre ellas.

Aplica una política de capacitación externa e interna para todos los colaboradores; lo cual indica que una de sus fortalezas estratégicas es el desarrollo de las destrezas de su fuerza laboral. A tratarse de una empresa de servicios, estos son su cara visible; los trabajadores son motivados gracias a una innovadora política de incentivos lo que conlleva a una mayor productividad y compromiso con los objetivos de la empresa; destacándose por la calidad humana de su personal y sustentando su desempeño en el sentido de equipo y de familia de sus trabajadores, aspecto que forma parte de su política para establecer y mantener una cultura corporativa moderna que apoye los objetivos y metas estratégicas. Su filosofía de trabajo responde a un compromiso permanente por generar una 
comunicación abierta y respetuosa dentro de la empresa, para alinear satisfactoriamente los intereses y las aspiraciones de los empleados con los objetivos y metas de la compañía.

Grupo Carvajal Colombia, Es un conglomerado multinacional, que marca la diferencia, con cerca de 24 mil colaboradores comprometidos con los resultados, cercanos a los clientes, y conscientes de la importancia de la sostenibilidad. Tiene presencia en 16 países de América Latina, a través de 8 negocios: Carvajal Educación, Carvajal Empaques, Carvajal Espacios, Carvajal Medios B2B, Carvajal Pulpa y Papel, Carvajal Soluciones de Comunicación, Carvajal Soluciones Educativas y Carvajal Tecnología y Servicios, y con marcas reconocidas como Norma, Jean Book,Reprograf, Propal, Earth Pact, Mepal, Tukasa, Almatec, Wau, Carpak y CEN. Carvajal es una empresa multinacional que, con sentido social y haciendo las cosas bien, contribuye a la productividad de sus clientes y al desarrollo de las personas, ofreciendo productos y servicios innovadores, competitivos y rentables para garantizar un desarrollo sostenible.

La resiliencia en el grupo Carvajal se evidencia a partir de la falta de suministro de materia prima que es la pulpa bagazo de caña como suministro para la elaboración del papel para la imprenta con la cual había iniciado operaciones en los años treinta. Esa falta de materia prima por un periodo afecto la producción que en su momento ya contaba con exportación. Para lo se evidencia los siguientes indicadores:

Liderazgo: implementa el plan estratégico: expansión en Colombia y en países de América Latina y el resto del mundo, ofreciendo productos y servicios integrales en material editorial y de soluciones modernas para la empresa.

Flexibilidad: se identifica a través de la creación de un clúster en la zona del Valle del Cauca en Colombia, donde inició sus actividades hace 100 años.

Capacidad instalada: Empresa que implemento la expansión multinacional integrada al $100 \%$ en todas sus funciones a partir de la transformación de insumos para las diferentes unidades de negocio.

Compromiso: implementación de capacitaciones y entrenamiento de su personal en todos los niveles de la organización. Actualización constante en los avances de la presentación de servicios.

Se rige por los siguientes valores: orientación al cliente, innovación, integridad, respeto y compromiso social. Sobre esta base, las empresas del grupo prestan especial atención 
constante a la capacitación y entrenamiento de su personal, ya que no solo se dedican a la producción de artículos de primera calidad sino a la prestación de servicios especializados. La actualización de sus trabajadores acerca de los últimos adelantos en materia de tecnología y de diseño es por tanto un factor clave para asegurar que el grupo.

Es preciso destacar que en todos los casos el componente de valores y cultura es indispensable y es una pieza clave para el éxito, todos estos grupos empresariales han desarrollado y aplicado acciones que fortalecen su compromiso social como una responsabilidad con la comunidad que va más allá de su papel como creadores de valor. ${ }^{25}$

\section{BIBLIOGRAFÍA}

Alvarez, J. (2014). Estrategias de desarrollo de Habilidades Directivas. Barcelona: Scoop.it!

Barquilla, J. C. (17 de 12 de 2014). Steelmood Business Process Resilience. Recuperado el 20 de 05 de 2015, de http://steelmood.blogspot.com/2014/12/resilienciaingenieria-psicologia-o.html

Bell, M. A. (2002). Gartner. The Five Principles of Organizational Resilience. New York.

Benimaclet, E. (29 de 05 de 2014). Blog de terapia y desarrollo personal. Recuperado el 20 de 05 de 2015, de https://eurekabenimaclet.wordpress.com/2014/05/

Brooks, R. \&. (2004). El poder de la resiliencia. Barcelona: Paidós.

Campo, R. G. (2012). Caracterización del avance teórico, investigativo y/o de intervención en resiliencia desde el ámbito de las universidades en Colombia. Bogotá: Universitas Psychologica.

Conrad, G. (2002). A Basic Assumptions and Terms.@ In R. R. Greene (Ed.). Resiliency: An integrated approach to practice, policy, and Research. Washington, DC: NASW Press.

Counsins, N. (1979). The anatomy of an illness as perceived by the patient. New York: Norton.

Cyrulnik, B. (2001). La maravilla del dolor: el sentido de la resiliencia. Barcelona: Granica.

Cyrulnik, B. T. (2004). El realismo de la esperanza. Testimonios de experiencias profesionales en torno a la resiliencia. Barcelona: Gedisa.

\footnotetext{
${ }^{25}$ Schneider Shpilberg, Ben. (2006). Resiliencia: como construir empresas exitosas en contextos de inestabilidad, pag 288, 321, 340.
} 
Dyer, J. y. (1996). Resilience: Analysis of the concept. Archive of Psychiatric Nursing.

Fisher, F. E. (2006). Mechanical Engineers' Handbook: Materials and mechanical design (en inglés). vol. I (3ª edición). Hoboken, NJ: John Wiley \& Sons, Inc.

Fraser, M. R. (1999). Risk, protection and resilience: Toward a conceptual framework for social work practice. Social.

George S. Everly, J. (24 de 06 de 2011). Harvard Business Review. Recuperado el 6 de 6 de 10, de https://hbr.org/2011/06/building-a-resilient-organizat

Grotberg, E. (1995). The international resilience project : Research, application, and policy. Lisbon, Portugal: Symposium International Stress e Violencia.

Grotberg, E. (1996). Guía de promoción de las resiliencia en los niños para fortalecer el espíritu humano (E. N. Suárez Ojeda, Trad.). La Haya: Fundación Bernard van Leer.

J. K. Felsman, y. G. (1987). Resilient children as adults: A 40-year study. New York: Guilford Press.

Kayes, C. (2015). Organizational Resilient. New York: Oxford University Press.

Kirby, L. y. (1997). Risk and resilience in childhood. En M. Fraser (Ed.), Risk and resilience in childhood. Washington, DC: NASW Press.

Kotliarenco, M. A. (2000). Actualizaciones en resiliencia. Buenos Aires: Ediciones de la UNLa.

Luthar, S. C. (2000). The construct of resilience: Implications for interventions and social policies. Development and Psychopatology.

M., R. (1990). sychosocial resilience and protective mechanisms. In: Rolf J, Masten AS, Cicchetti $D$, Nuechterlein $K H$, Weintraub $S$, editors. Risk and protective factors in the development of psychopathology. Cambridge: New York.

Masten, A. y. (1998). The development of competence in favorable and unfavorable environments. American Psychologist.

Milgram, N. A. (1993). Psychosocial characteristics of resilient children. Journal of. New York.

MSc, J. M. (2008). Organizational Resilience: the Key to Anticipation, Adaptation and Recovery. Inglaterra: Cranfield School of Management.

Osborn, A. (1993). Resiliencia y estrategias de intervención. Universidad de Bristol: Escuela de Educación en Resiliencia.

OSBORN, A. (1993). Resiliencia y estrategias de intervención. Universidad de Bristol: Escuela de Educación en Resiliencia.

Quesada, C. V. (2003). UAEM Redalyc.org. Obtenido de El concepto de resiliencia individual y familiar. Aplicaciones en la intervención social:

http://www.redalyc.org/articulo.oa?id=179818049003 
Quesada, C. V. (2006). El Enfoque de Resiliencia en Trabajo Social. España.

RAE. (2015). Real Academia Española. Recuperado el 15 de 7 de 2015, de http://lema.rae.es/drae/?val=RESILIENCIA

Resilient Organizations. (2012). Recuperado el 2015 de 05 de 10, de http://www.resorgs.org.nz/

Robert, B. (2010). Organizational Resilient - Concepts and evaluation method. Canada: Concepts and evaluation method.

Rosales, P. P. (2015). Instituto Español de Resiliencia. Recuperado el 10 de 6 de 2015, de http://resiliencia-ier.es/faqs

Rutter. (1990). sychosocial resilience and protective mechanisms. In: Rolf J, Masten AS, Cicchetti $D$, Nuechterlein $K H$, Weintraub S, editors. Risk and protective factors in the development of psychopathology. Cambridge: New York.

Rutter, M. (1985). Resilience in the face of adversity: Protective factors and resistance to psychiatric disorder. British Journal of Psychiatric,.

Saavedra, E. \&. (2008a). Escala de Resiliencia SV-RES, para jóvenes y adultos. Santiago: CEANIM.

Saavedra, E. \&. (s.f.). Jóvenes infractores de ley, resiliencia y educación. Ponencia presentada en las VIII Jornadas Internacionales de Psicología. Lima, Perú.

Saavedra, E. (2003). El Enfoque Cognitivo Procesal Sistémico, como posibilidad de intervenir educativamente en la formación de sujetos resilientes: estudio de casos. España: Tesis Doctoral, Universidad de Valladolid.

Salgado, C. M. (09 de 2010). LA RESILIENCIA Y SU EMPLEO EN LAS ORGANIZACIONES. Recuperado el 20 de 05 de 2015, de Factorhuma.org: http://www.factorhuma.org/attachments_secure/article/8264/resiliencia_cast.pdf

Suárez, E. K. (1995). El enfoque de riesgo y su aplicación a las conductas del adolescente. Una perspectiva psico-social. Publicaciones Científicas.

SUÁREZ, E. K. (1995). El enfoque de riesgo y su aplicación a las conductas del adolescente. Una perspectiva psico-social. Publicaciones Científicas.

TidalShift. (2015). TidalShift. Recuperado el 2015 de 5 de 6, de http://www.tidalshift.ca/organizational-lift-theory/

UNAD. (1 de 2004). Universidad Nacional Abierta a Distancia. Recuperado el 15 de 6 de 2015, de http://datateca.unad.edu.co/contenidos/434202/2013_2/RESILIENCIA_APLICADA _A_LA_INTERVENCION_SOCIAL_LEU2_.pdf

UNICEF. (2004). ¿Quién dijo que no se puede? Escuelas efectivas en sectores de pobreza. Recuperado el 20 de 05 de 2015, de http://scholar.google.com/scholar?hl=en\&btnG=Search\&q=intitle:¿Quién+dijo+que +no+se+puede?+Escuelas+efectivas+en+sectores+de+pobreza\#0 
Unit, E. I. (2007). Best practice in risk management. Estados Unidos: The Economist.

Vanistendael, S. (1994). Como crecer superando los percances. Resiliencia: Capitalizar las fuerzas del individuo. Cuadernos del Bice.

Vanistendael, S. (1994). Resilience: a few key. Barcelona: International Catholic Child Bureau.

Villalta, M. (2009). Factores de resiliencia en estudiantes secundarios. Una propuesta de medición. Santiago: Universidad del Desarrollo.

Walsh, F. (1998). Strengthening family resilience. New York: Guilford Press.

Walsh, F. (2004). Living Beyond Loss: Death in the Family. New York.

White, M. (2013). Building a Resilient Organizational Culture. Recuperado el 2015 de 5 de 6 , de file:///C:/Users/admin/Downloads/Building-a-Resilient-Organizational-Culturefinal.pdf 